\title{
Longevity Manipulations Differentially Affect Serotonin/ Dopamine Level and Behavioral Deterioration in Aging Caenorhabditis elegans
}

\author{
Jiang-An Yin, ${ }^{1,2 *}$ Xi-Juan Liu, ${ }^{1 *}$ Jie Yuan, ${ }^{1,2}$ Jing Jiang, ${ }^{1}$ and Shi-Qing Cai ${ }^{1}$ \\ ${ }^{1}$ Institute of Neuroscience and State Key Laboratory of Neuroscience, Shanghai Institutes for Biological Sciences, Chinese Academy of Sciences, Shanghai \\ 200031, China, and 2University of Chinese Academy of Sciences, Shanghai 200031, China
}

\begin{abstract}
Aging is accompanied with behavioral and cognitive decline. Changes in the neurotransmitter level are associated with the age-related behavioral deterioration, but whether well-known longevity manipulations affect the function of neurotransmitter system in aging animals is largely unclear. Here we report that serotonin (5-HT) and dopamine (DA) level decrease with age in C. elegans. The reduction results in downregulation of the activity of neurons controlled by 5-HT/DA signaling, and deterioration of some important behaviors, including pharyngeal pumping, food-induced slowing responses, and male mating. Longevity manipulations differentially affect the age-related decline in neuronal level of 5-HT/DA. The reduction and resultant behavioral deterioration occur in long-lived worms with defective insulin signaling [daf-2(e1370), age-1(hx546)] or mitochondria function [isp-1(qm150), tpk-1(qm162)], but not in long-lived worms with dietary restriction eat-2(ad1116). A reduced expression level of dopa decarboxylase BAS-1, the shared enzyme for 5-HT/DA synthesis, is responsible for the decline in 5-HT/DA levels. RNAi assay revealed that the sustained 5-HT/DA level in neurons of aged eat-2(ad1116) worms requires PHA-4 and its effectors superoxide dismutases and catalases, suggesting the involvement of reactive oxygen species in the 5-HT/DA decline. Furthermore, we found that elevating 5-HT/DA ameliorates age-related deterioration of pharyngeal pumping, food-induced slowing responses, and male mating in both wild-type and daf-2(e1370) worms. Together, dietary restriction preserves healthy behaviors in aged worms at least partially by sustaining a high 5-HT/DA level, and elevating the 5-HT/DA level in wild-type and daf-2(e1370) worms improves their behaviors during aging.
\end{abstract}

\section{Introduction}

Aging is characterized by the progressive decline in behavioral and cognitive functions. Functional imaging studies reveal a global loss of activity in many brain regions in aged human subjects (Andrews-Hanna et al., 2007; Bishop et al., 2010; Grady, 2012; Morrison and Baxter, 2012). Recent evidence suggests that, in most cortical regions of aging brain, morphological and physiological changes at synapses, rather than neuronal loss, are the cellular basis of age-related alteration in connectivity and integrative function (Andrews-Hanna et al., 2007; Bishop et al., 2010; Grady, 2012; Morrison and Baxter, 2012).

Received Sept. 19, 2013; revised Jan. 13, 2014; accepted Feb. 4, 2014.

Author contributions: J.-A.Y. and S.-Q.C. designed research; J.-A.Y., X.-J.L., J.Y., and J.J. performed research; J.-A.Y. and S.-Q.C. analyzed data; J-A.Y. and S.-Q.C. wrote the paper.

This work was supported by the Hundred Talent Program to S.- O.C., Chinese Academy of Sciences, and State Key Laboratory of Neuroscience, Chinese government. We thank Drs. Ji Ying Sze and Loren Looger for the gifts of tph-1 and G-CaMP3 constructs, respectively; Drs. Mu-ming Poo, Federico Sesti, Ying Liu, and Di Chen for critical reading of the manuscript; Drs. Cheng-yu Li and Qian Hu for help with calcium imaging; Songlin Qian and Chunling Li for help with HPLC experiments; and Dr. S. Mitani (Tokyo Women's Medical University School of Medicine) and the C. elegans Genetics (enter (funded by the National Institutes of Health) for providing us strains.

The authors declare no competing financial interests.

*J.-A.Y. and X.-J.L. contributed equally to this work.

Correspondence should be addressed to Dr. Shi-Qing Cai, 320 Yueyang Road, Biological Research Building, Room 505, Shanghai, China 200031. E-mail: sqcai@ion.ac.cn.

DOI:10.1523/JNEUROSCI.4013-13.2014

Copyright $\odot 2014$ the authors $\quad 0270-6474 / 14 / 343947-12 \$ 15.00 / 0$
Reduction of neurotransmitter signaling has been consistently observed in the aging brain, although the extent of reduction varies among different neurotransmitters and across brain regions (Makman and Stefano, 1993). Both animal models and human studies (Wong et al., 1984; Rinne et al., 1990; Wang et al., 1998; Kaasinen et al., 2000; Ota et al., 2006; Kumakura et al., 2010) indicate a significant decline in dopamine synthesis and its receptor level in aged nervous systems. In the prefrontal cortex of humans and rhesus monkeys, there is an age-dependent downregulation of genes involved in GABA transmission that could alter the balance between inhibitory and excitatory neurotransmission (Lu et al., 2004). Attenuation of serotonergic receptors has also been consistently reported in the aging brain (Meltzer et al., 1998). Previous studies have established a correlation between dopamine decline and age-related behavioral alterations, including the changes in reward system and working memory (Braskie et al., 2008; Dreher et al., 2008). However, in long-lived animal models caused by food restriction and by gene mutations that result in decreased insulin signaling or mitochondrial function (Lin et al., 1997; Feng et al., 2001; Fontana et al., 2010; Kenyon, 2010), it is unknown whether there is alteration in neurotransmitter systems related to lifespan extension and whether such alteration affects behavioral deterioration.

The Caenorhabditis elegans nervous system uses an array of neurotransmitters, receptors, and downstream signaling mecha- 
nisms that are similar to those identified in the mammalian brain (Chase and Koelle, 2007). In this study, we found long-lived mutants with reduced insulin signaling or mitochondrial function showed similar age-dependent decline in 5-HT and DA level with that in wild-type N2 worms. Surprisingly, worms with dietary restriction (DR) showed no decline in 5-HT/DA level, and longevity regulator PHA-4 upregulated the synthesis of 5-HT/DA specifically in late adulthood of these DR worms. Furthermore, we found that elevation of endogenous 5-HT/DA helped to preserve several important behaviors, including slowing responses to food, pharyngeal pumping, and male mating, all of which showed deterioration in both aged wild-type and long-lived daf-2(e1370) animals. Thus, we have revealed that longevity genes differentially affect 5-HT/DA level and elevation of these transmitters could promote healthy behaviors in aging C. elegans.

\section{Materials and Methods}

C. elegans strains and culture. N2, daf-2(e1370), age-1(hx546), isp1(qm150), tpk-1(qm162), eat-2(ad1116), eat-2(ad465), bas-1(ad446), tph-1(mg280), unc-54(e190), and TU3401 strains were obtained from the Caenorhabditis Genetics Center. Animals were cultivated at $20^{\circ} \mathrm{C}$ on standard NGM plates with OP50 Escherichia coli and developmentally synchronized by hypochlorite treatment. Unless specifically pointed out, day 0 animals were $L 4$ hermaphrodites and synchronized animals at day 1 and 9 of adulthood were referred as young and aged worms, respectively. For $\mathrm{Ca}^{2+}$ imaging experiments, unc-54(e190) worms were moved to NGM containing $20 \mu \mathrm{M}$ FUdR at the L4 stage and raised at $20^{\circ} \mathrm{C}$.

Constructs. $P_{\text {bas- } 1}::$ bas- $1:: g f p$ transgenic plasmid was generated by joining $4.6 \mathrm{~kb}$ bas-1 upstream promoter and full-length bas-1 DNA with GFP reporter gene in the PPD 95.75 vector. The bas-1 promoter and bas- 1 gene were amplified by PCR from genomic DNA of wild-type N2 worm by the following primers: forward, $5^{\prime}$-acatgcatgcgacaacgaattcgctcattc- $3^{\prime}$ and reverse, $5^{\prime}$-acccccgggtataccgaactactactgaaag- $3^{\prime}$ for bas-1 promoter; and forward, $5^{\prime}$-acccccgggatggactcccaaaaattgcg- $3^{\prime}$ and reverse, $5^{\prime}$-gaactcgc cgagaaattattcctaccggtgc- $3^{\prime}$ for bas-1 gene. To construct $P_{t p h-1}::$ bas-1::gfp

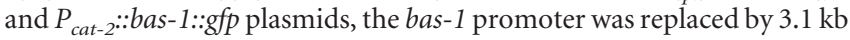
tph-1 and $2.2 \mathrm{~kb}$ cat-2 gene upstream promoters, respectively. The primers for $P_{t p h-1}$ are as follows: forward, $5^{\prime}$-acatgcatgctcggtggtcttcccgcttgc- $3^{\prime}$ and reverse, $5^{\prime}$-ccccccgggatgattgaagagagcaatgc- $3^{\prime}$; for $P_{\text {cat }-2}$; forward, $5^{\prime}$ acgcgtcgacacacgccaacttccacttgg- $3^{\prime}$ and reverse, $5^{\prime}$-accccogggttaattgag acgttccttgcg- $3^{\prime} . P_{\text {unc-1 } 19}:$ :sid-1 was constructed following the method reported previously (Calixto et al., 2010), and $P_{t p h-1}:: t p h-1:: g f p$ is a gift from Dr. Ji Ying Sze.

$P_{f l p-21}::$ gcamp 3 and $P_{f l p-21}:: d s r e d 2$ expression plasmids were generated by joining $2.7 \mathrm{~kb}$ of $f l p-21$ upstream promoter and full-length gcamp 3 or dsred 2 cDNA in the pPD 95.75 vector. The $f l p-21$ promoter was amplified by PCR from N2 genomic DNA using the following primers: forward, $5^{\prime}$-aaaactgcagaactaggtccagtgaccgaa- $3^{\prime}$ and reverse, $5^{\prime}$-acgcgtcgaccgtctga aaatgactttttgg- $3^{\prime}$. All the DNA fragments generated by PCR were verified by sequencing.

Generation of transgenic animals. The expression constructs were injected into N2 worms by standard methods. $P_{\text {bas }-1}:: b a s-1:: g f p$, $P_{t p h-1}::$ bas-1::gfp, $P_{\text {cat }-2}: \because$ bas- $1:: g f p, P_{f l p-21}:: g$ camp 3 , and $P_{f l p-21}:: d s r e d 2$ were injected at $50,50,50,28$, and $23 \mathrm{ng} / \mu \mathrm{l}$, respectively. Transient transgenic $P_{\text {bas }-1}::$ bas- $1:: g f p, P_{t p h-1}::$ bas $-1:: g f p$, and $P_{\text {cat }-2}:: b a s-1:: g f p$ worms were integrated using the UV/TMP method and outcrossed four times. The $P_{\text {bas }-1}::$ bas-1::gfp transgenic worm was then crossed with daf-2(e1370) and eat-2(ad1116) mutants to obtain daf-2(e1370); $P_{\text {bas }-1}::$ bas- $1:: g f p$ and eat-2(ad1116); $P_{\text {bas }-1}:: b a s-1:: g f p$ worms, respectively; $P_{t p h-1}:: b a s-1:: g f p$ transgenic worm was crossed with daf-2(e1370) to obtain

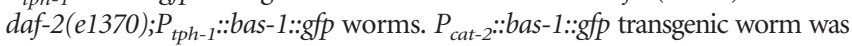

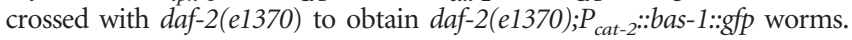
TU3401 was crossed with eat-2(ad1116) to obtain eat-2(ad1116);TU3401 worms. For $\mathrm{Ca}^{2+}$ imaging, $P_{f p-21}::$ : $c$ camp 3 and $P_{f t p-21}:: d s r e d 2$ were coinjected into N2 worms and then crossed into unc-54(e190) to minimize locomotion of the worms.
Serotonin immunostaining and formaldehyde-induced fluorescence. The immunostaining procedure was performed as described previously (Loer and Kenyon, 1993). DA was stained by a formaldehyde-induced fluorescence (FIF) technique as previously described (Lints and Emmons, 1999).

High-performance liquid chromatography (HPLC). Synchronized populations of young adult or aged C. elegans were harvested and washed with M9 buffer $\left(22 \mathrm{~mm} \mathrm{KH}_{2} \mathrm{PO}_{4}, 34 \mathrm{~mm} \mathrm{~K}_{2} \mathrm{HPO}_{4}, 86 \mathrm{~mm} \mathrm{NaCl}, 1 \mathrm{~mm}\right.$ $\mathrm{MgSO}_{4}$ ) for several times to remove bacteria. Worms were sonicated in $300 \mu$ l of 0.3 м perchloric acid (containing 2 mM EDTA) and then centrifuged at $17,000 \times g$ for $15 \mathrm{~min}$. Samples were filtered, cooled to $4^{\circ} \mathrm{C}$, and $25 \mu \mathrm{l}$ was used for HPLC injection. Identification and quantification of DA and 5-HT were achieved by comparing peak characteristics of samples with the respective commercial standards (Sigma). The total protein level was measured by the Bradford method.

Calcium imaging. To measure the neuronal activity, $\mathrm{Ca}^{2+}$ indicator G-CaMP3 (Tian et al., 2009) and DsRed2 were specifically expressed in MC neurons of unc-54(e190) worms by flp-21 upstream promoter. For living worm experiments, well-fed worms were transferred to 2-mmthick NGM plates, and their slight locomotion was restricted by surrounding bacteria OP50. For exogenous 5-HT treatment experiment, the pharynx was dissected with an injection syringe needle under Dent's saline (composition in mM as follows: D-glucose 10, HEPES 10, $\mathrm{NaCl} 140$, $\mathrm{KCl} 6, \mathrm{CaCl}_{2} 3, \mathrm{MgCl}_{2}$ 1, pH 7.4 with $\mathrm{NaOH}$ ) containing $5 \mu \mathrm{M} \mathrm{5-HT}$. Images were captured by Nikon A1R laser scanning confocal imaging system at $27 \mathrm{~Hz}$. A $20 \times$ objective lens in conjunction with a $20 \times$ zoom was used to acquire images. G-CaMP3 and DsRed2 were excited at 488 and $543 \mathrm{~nm}$, respectively. We used PFS to track fluorescent targets and recorded neuronal $\mathrm{Ca}^{2+}$ transient $\sim 1 \mathrm{~min}$ for each worm. Image stacks in the most immobile $10 \mathrm{~s}$ were selected for data analysis. The ratio of G-CaMP3/DsRed2 fluorescence of ROI in stacks was sorted in ascending order by stacksorter (ImageJ, National Institutes of Health), and the first 15 images of the sorted stacks were averaged to set as $\mathrm{R}_{0}$. The frequency, power spectrum of $\mathrm{Ca}^{2+}$ transients were calculated by MATLAB (matrix laboratory), and figures were prepared by Igor Pro (Wavemetrix).

$q R T-P C R$. More than 400 well-fed synchronized worms on day 1 and 9 of adulthood were picked into a $1.5 \mathrm{ml}$ Eppendorf tube and then washed three times with M9 buffer. Total RNA was extracted with RNeasy mini kit (QIAGEN) and $1 \mu \mathrm{g}$ of total RNA was reversetranscribed with QuantiTect Rev. Transcription kit (QIAGEN). Realtime PCR was performed on a Roche LightCycler 480 system using SYBR Green (Takara). The act-1 gene was used as an internal control for RT-PCR.

Pumping rate assay. Pharyngeal pumping was recorded by counting the number of pharyngeal contractions during a $10 \mathrm{~s}$ interval under dissection microscope. Isolated pharynx was dissected by an injection syringe needle under Dent's saline and its pharyngeal pumping rate was recorded in the presence of various concentration of 5-HT.

Basal and enhanced slowing responses. Basal (BSR) and enhanced (ESR) slowing responses were performed as previously described (Sawin et al., 2000), except a slight modification for exogenous neurotransmitter treatment. Freshly prepared 5-HT or DA solution (dissolved in M9 buffer) was added to a seeded plate to obtain an equilibrium concentration of $\sim 2.5 \mathrm{~mm}$ of the either neurotransmitter. Approximately 50 aged animals of each genotype were transferred to pretreated plates. After $7 \mathrm{~h}$, BSR and ESR behaviors of these animals were tested. All experiments were repeated by two people without knowledge of worm genotype and the neurotransmitter content of the pretreatment plates. Statistical analysis was performed using the unpaired Student's $t$ test.

$D R$. DR was performed on solid plate following the previously reported method (Chen et al., 2009) with slight modifications. Briefly, $1.0 \times 10^{11}$ and $1.0 \times 10^{9} \mathrm{cfu} / \mathrm{ml}$ bacteria were used as ad libitum (AL) and DR conditions, respectively. The $250 \mu \mathrm{l}$ bacterial cultures were spotted onto $60 \mathrm{~mm}$ standard NGM plates containing $20 \mu \mathrm{M}$ FUdR and $50 \mu \mathrm{g} / \mathrm{ml}$ carbenicillin. Approximately 300 synchronized L4 wild-type N2 larvae growing under normal condition were transferred to $10 \mathrm{AL}$ or DR plates (30 worms per plate) and changed to new AL or DR plates every other day.

RNAi by feeding. RNAi feeding was performed as previously described (Calixto et al., 2010) with the following modifications. Briefly, bacteria 

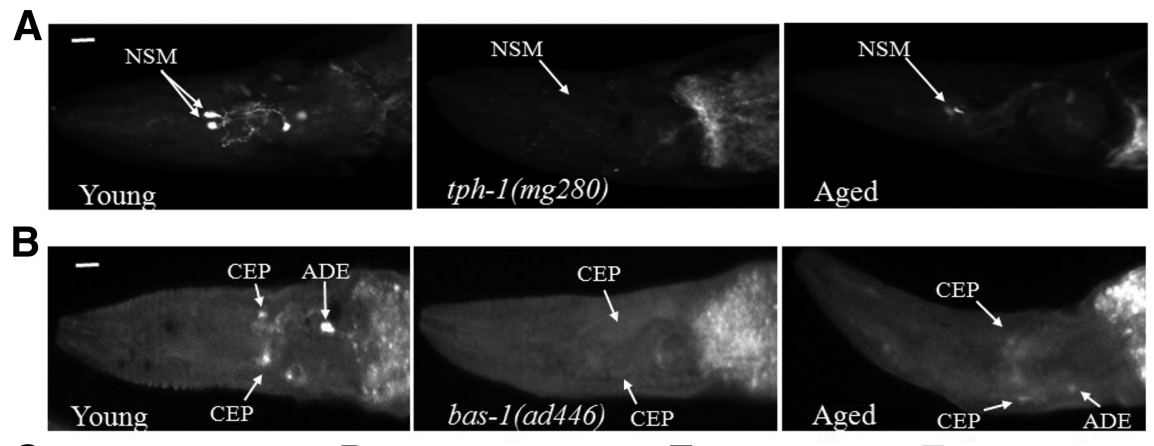

C
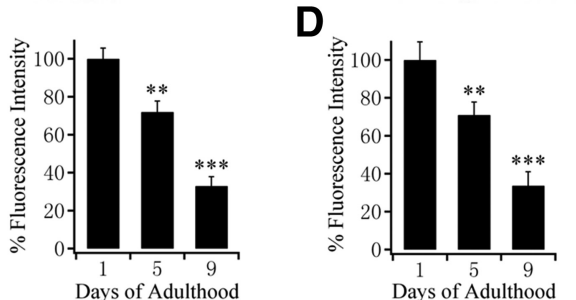

E

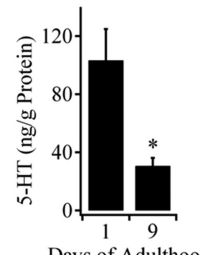

Figure 1. Neuronal level of 5-HT and DA decreases with age. $\boldsymbol{A}$, Immunostaining of serotonergic neurons in young adult N2, young adult tph-1(mg280), and aged N2 worms. B, FIF staining of dopaminergic neurons in young adult N2, young adult bas1(ad446), and aged N2 worms. $\boldsymbol{A}, \boldsymbol{B}$, Scale bar, $10 \mu \mathrm{m}$. C, Quantitative analysis of 5-HT level in NSM neurons of N2 worms at day 1 ( $n=30$ worms), day 5 (72 $\pm 6 \%$ of that in young adult worms, $n=21$ worms), and day 9 adulthood ( $33 \pm 5 \%$ of that in young adult worms, $n=40$ worms). 5 -HT level was determined by immunostaining. $\boldsymbol{D}$, Quantitative analysis of DA level in (EP neurons of $\mathrm{N} 2$ worms at day 1 ( $n=28$ worms), day 5 ( $71 \pm 6 \%$ of that in young adult worms, $n=24$ worms), and day 9 adulthood (34 $\pm 6 \%$ of that in young adult worms, $n=35$ worms). DA level was determined by FIF staining. $\boldsymbol{C}, \boldsymbol{D}$ Normalized fluorescence was obtained by dividing individual values with average fluorescence intensity of wild-type worms at day 1 of adulthood. $\boldsymbol{E}$, Quantification of $5-\mathrm{HT}$ content in young adult (103 $\pm 21 \mathrm{ng} / \mathrm{g}$ protein) and aged ( $31 \pm 5$ $\mathrm{ng} / \mathrm{g}$ protein) N2 worms using HPLC. $\boldsymbol{F}$, Quantification of DA content in young adult (587 $\pm 42 \mathrm{ng} / \mathrm{g}$ protein) and aged ( $244 \pm 70 \mathrm{ng} / \mathrm{g}$ protein) N2 worms using HPLC. $\boldsymbol{E}, \boldsymbol{F}$, Data were average of five independent experiments. In all cases, day 0 animals were WT L4 hermaphrodites; young and aged worms represent the worms in day 1 and 9 of adulthood of all strains, respectively. Data are mean $\pm S E .{ }^{*} p<0.05$ (unpaired Student's $t$ test). ${ }^{* *} p<0.01$ (unpaired Student's $t$ test). ${ }^{* * *} p<0.001$ (unpaired Student's $t$ test).

expressing dsRNA targeting longevity genes, taken from the Ahringer library (Kamath et al., 2003), were grown on LB plates supplemented with $100 \mu \mathrm{g} / \mathrm{ml}$ carbenicillin and $12.5 \mu \mathrm{g} / \mathrm{ml}$ tetracycline at $37^{\circ} \mathrm{C}$ overnight. The next day, a single clone was grown in LB liquid supplemented with $100 \mu \mathrm{g} / \mathrm{ml}$ carbenicillin for $10-12 \mathrm{~h}$. The culture was then seeded onto NGM plates containing $1 \mathrm{mM}$ IPTG, $50 \mu \mathrm{g} / \mathrm{ml}$ carbenicillin, and 20 $\mu \mathrm{M}$ FUdR, and allowed to grow for $48 \mathrm{~h}$ before RNAi assays. L4 eat-2(ad1116); $P_{\text {bas }-1}::$ bas-1::gfp; $P_{\text {unc-119 }}:$ sid-1 hermaphrodites were washed and transferred onto plates containing bacteria expressing dsRNA. The BAS-1 level of the transgenic worms was determined after treatment with dsRNAs targeting longevity genes for 4 and $9 \mathrm{~d}$. All clones used for RNAi were confirmed by sequencing.

Paraquat and DTT treatment. Briefly, $P_{\text {bas- } 1}::$ bas-1::gfp, $P_{t p h-1}:: t p h-$ $1:: g f p$, and eat-2(ad1116); $P_{\text {bas }-1}:: b a s-1:: g f p$ transgenic worms at day 1 or day 2 of adulthood were placed on OP50-seeded plates containing various concentrations of paraquat $(2,4$, and $6 \mathrm{mM})$ and $20 \mu \mathrm{M}$ FUdR. For DTT treatment, $P_{b a s-1}: \because$ bas-1::gfp transgenic worms at day 6 adulthood were transferred to OP50-seeded plates containing various concentrations of DTT $(0.5,1,3$, and $5 \mathrm{~mm})$ and $20 \mu \mathrm{M}$ FUdR. Three days after treatments, the BAS-1::GFP level was analyzed.

Mating behavior. Mating behavior was conducted as previously described (Guo et al., 2012). Briefly, 200 males were isolated at L4 in four $60 \mathrm{~mm}$ plates $\left(\sim 50\right.$ males per plate) and raised at $20^{\circ} \mathrm{C}$. Two males and two young N2 hermaphrodites were picked into a $35 \mathrm{~mm}$ NGM plate with 5-mm-diameter lawn (10 $\mu$ l OP50 bacteria was spotted onto NGM plate, allowed to grow 16-24 h). Male worms were picked out $24 \mathrm{~h}$ later, and the mating efficiency was scored $4 \mathrm{~d}$ later. For 5-HT treatment, males at different ages were raised on plates containing $2.5 \mathrm{~mm} 5$-HT for 5-7 h and then used for mating behavioral assays. Mating efficiency was calculated as follows: mating efficiency $=$ (number of successful mating plates/number of all mating plates $) \times 100 \%$.
$F$

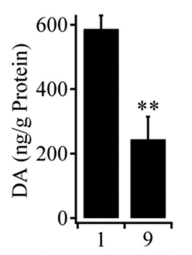

Days of Adulthood

Lifespan assay. For lifespan assay, $\sim 90$ worms were cultivated on three OP50 seeded plates ( 30 worms per plate) at $20^{\circ} \mathrm{C}$ with FUdR. For exogenous 5-HT treatment, worms at day 5 of adulthood were transferred to cultivating plates containing 0.1 or $0.5 \mathrm{~mm} 5-\mathrm{HT}$. Worms were judged as dead when they did not respond to repeated prodding with a pick. Dead worms were counted daily. Animals that crawled off the plates were not included in the analysis.

\section{Results}

\section{Neuronal level of 5-HT and DA} decreases with age

The neuronal level of 5-HT was examined by immunostaining C. elegans of different ages with anti-serotonin antibody. Synchronized C. elegans hermaphrodites at day 1 and 9 of adulthood were referred to hereafter as young and aged worms, respectively. We found that 5-HT-stained serotonergic neurons were clearly visible in young adult wild-type (N2) worms but absent in young adult tph-1(mg280) mutants, which do not synthesize 5-HT (Sze et al., 2000) (Fig. 1A), indicating specificity of immunostaining. Compared with young adults, aged N2 worms showed weaker staining (Fig. 1A). We then measured the fluorescence intensity at the soma of two major 5-HT-containing neurons, known as NSM neurons (Horvitz et al., 1982), in N2 worms of different ages, and found that the 5-HT level in these neurons of worms at day 5 and day 9 of adulthood was $72 \pm 6 \%$ and $33 \pm 5 \%$ of that in young adult (day 1 of adulthood) worms, respectively (Fig. $1 C)$.

Using the FIF method, we found that dopaminergic CEP neurons, which are known to be involved in touch sensation (Sulston et al., 1975), in N2 young adults exhibited a high-level DA fluorescence, but the fluorescence was absent in young adult bas-1 (ad446) mutant worms with defective DA synthesis (Loer and Kenyon, 1993) (Fig. 1B). The aged N2 worms showed a lower level of fluorescence (Fig. 1B). Measurements of the fluorescence intensity at the soma of CEP neurons showed that the DA level in these neurons of worms at day 5 and day 9 of adulthood was $71 \pm$ $6 \%$ and $34 \pm 6 \%$ of that in young adult (day 1 of adulthood) worms, respectively (Fig. 1D). Therefore, the level of their respective transmitters in 5-HT and DA neurons markedly decreases with age.

We further measured 5-HT and DA contents in worms using HPLC. The amount of 5-HT was $103 \pm 21$ and $31 \pm 5$ $\mathrm{ng} / \mathrm{g}$ protein for $\mathrm{N} 2$ worms at day 1 and day 9 of adulthood, respectively (Fig. 1E). Similarly, the DA level decreased to $244 \pm 70 \mathrm{ng} / \mathrm{g}$ protein in worms at day 9 of adulthood from the level of $587 \pm 42 \mathrm{ng} / \mathrm{g}$ protein in young adult (day 1 of adulthood) worms (Fig. $1 F$ ). The extents of age-related changes in 5-HT/DA determined by HPLC and immunostaining/FIF are comparable, further confirming that the level of 5-HT and DA declines with age in C. elegans. We used immunostaining/FIF methods to determine the level of 5-HT and DA hereafter, respectively, because they are relatively convenient and can visualize 5 -HT/DA in neurons. 
A

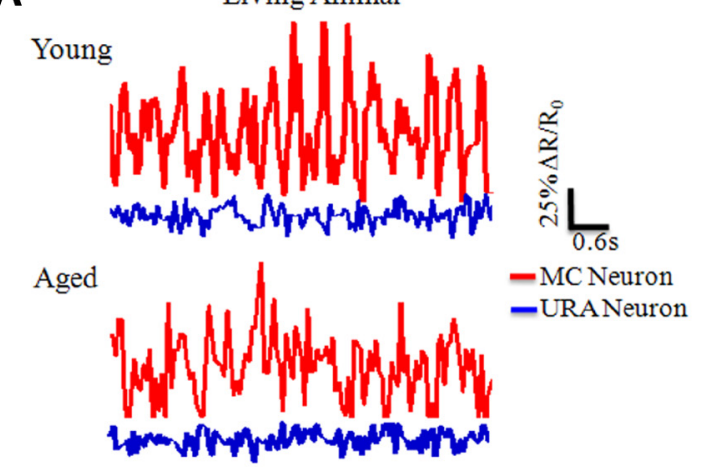

C

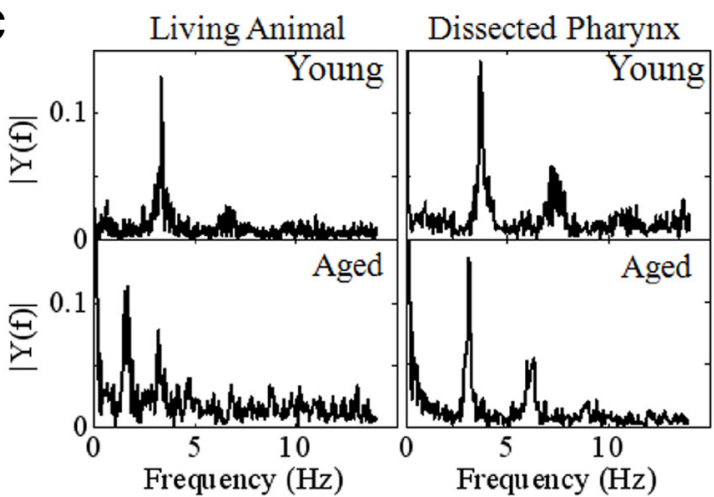

B

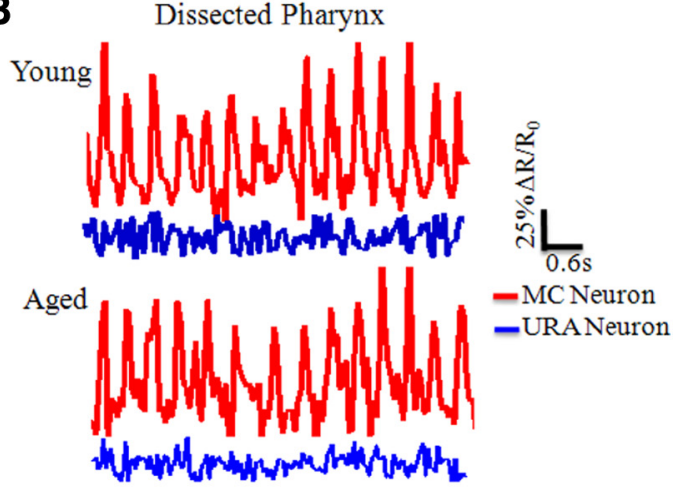

D

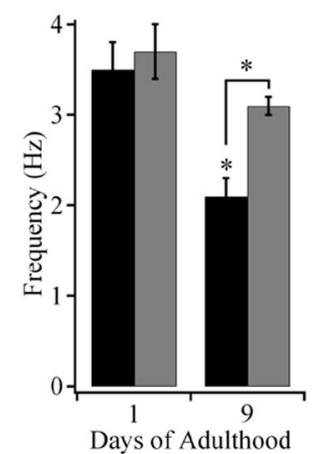

E $\quad$ Living Animal

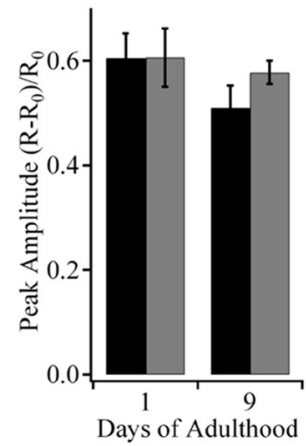

Figure 2. L Loss of 5-HT downregulates activity of MC neurons in aged worms. $A$, Changes in $\Delta R / R_{0}$ at pharyngeal pacemaker $M C$ (red line) and nonpharyngeal URA (blue line) neurons of young adult ( $n=13$ worms) and aged ( $n=10$ worms) normal feeding unc-54(e190) worms. R, Ratio of G-CaMP3/DsRed2 fluorescence. $B$, Changes in $\Delta R / R_{0}$ at MC and URA neurons in dissected pharynxes from young adult ( $n=6$ worms) and aged ( $n=8$ worms) unc-54(e190) worms in the presence of $5 \mu \mathrm{M} 5$-HT. C, Power spectrum of $\Delta \mathrm{R} / \mathrm{R}_{0}$ in MC neurons of normal feeding unc-54(e190) animals and dissected pharynxes. $\boldsymbol{D}$, Frequency of $\mathrm{Ca}^{2+}$ oscillation in MC neurons of normal feeding unc-54(e190) animals and dissected pharynxes. The average frequency of $\mathrm{Ca}^{2+}$ oscillation was $3.5 \pm$ $0.3,2.1 \pm 0.2,3.7 \pm 0.3$, and $3.1 \pm 0.1 \mathrm{~Hz}$ for young normal feeding worms, aged normal feeding worms, young dissected pharynxes, and aged dissected pharynxes, respectively. $\boldsymbol{E}$, Amplitude of $\mathrm{Ca}^{2+}$ oscillation in MC neurons of normal feeding unc-54(e190) animals and dissected pharynxes. The average amplitude $\left(\Delta \mathrm{R} / \mathrm{R}_{0}\right)$ of $\mathrm{Ca}{ }^{2+}$ oscillation was $0.61 \pm 0.06,0.51 \pm 0.06,0.61 \pm 0.09$, and $0.58 \pm 0.04$ for young normal feeding worms, aged normal feeding worms, young dissected pharynxes, and aged dissected pharynxes, respectively. Data are mean \pm SE. ${ }^{*} p<0.01$ (unpaired Student's $t$ test).

\section{Loss of 5-HT decreases neuronal activity of its target neurons} during aging

Serotonin regulates pharyngeal pumping via activating its target neurons, including MC pharyngeal motoneurons, which function as the pacemaker for the pharyngeal pumping rhythms (Avery and Horvitz, 1989). To ascertain whether the loss of 5-HT affects the function of MC neurons, we monitored their activity during pharyngeal pumping with ratiometric $\mathrm{Ca}^{2+}$ imaging, by expressing the $\mathrm{Ca}^{2+}$ indicator protein G-CaMP3 (Tian et al., 2009) in MC neurons (via flp-21 promoter) together with DsRed2, following the method reported previously (Rogers et al., 2003). To minimize the confounding effect of worm movement during $\mathrm{Ca}^{2+}$ imaging, we used unc54(e190) mutants that are paralyzed but retain largely normal pharyngeal pumping. We found that $\mathrm{Ca}^{2+}$ signals in $\mathrm{MC}$ neurons exhibited large rhythmic oscillation, which is in phase with the rhythm of pharyngeal pumping activity (Fig. $2 A, B$ ). In adjacent nonpharyngeal URA neurons, which also expressed G-CaMP3/DsRed2, no significant $\mathrm{Ca}^{2+}$ transient was observed (Fig. $2 A, B$ ). Thus, $\mathrm{Ca}^{2+}$ oscillation in MC neurons represents specific neuronal activity controlling pharyngeal pumping.

The MC neurons of young adult living worms with normal feeding displayed fast and robust $\mathrm{Ca}^{2+}$ oscillation in MC but not adjacent URA neurons (Fig. 2A), similar to that observed in the terminal bulb and the anterior isthmus of pharyngeal muscle
(Shimozono et al., 2004). Consistent with the age-dependent reduction in the pharyngeal pumping rate (Huang et al., 2004) and also Figure $3 A$, we found that the $\mathrm{Ca}^{2+}$ oscillation in MC neurons showed irregular rhythm in aged worms (Fig. 2A), with distinct alteration in the power spectrum of the oscillation (Fig. $2 C$ ). The average frequency of $\mathrm{Ca}^{2+}$ oscillation in $\mathrm{MC}$ neurons significantly decreased with age, and the values were $3.5 \pm 0.3$ and $2.1 \pm$ $0.2 \mathrm{~Hz}$ for young and aged normal feeding worms, respectively (Fig. 2D). The amplitude of the oscillation, however, did not significantly change with age (Fig. $2 E$ ).

The role of 5-HT in age-dependent downregulation of $\mathrm{MC}$ neuronal activity was further examined by using the preparation of dissected pharynx. In the presence of 5-HT ( $5 \mu \mathrm{M})$, dissected pharynxes from both young and aged adult worms showed similar patterns of pharyngeal pumping and $\mathrm{Ca}^{2+}$ oscillation in $\mathrm{MC}$ neurons with those observed in living young adult worms (Fig. $2 A-E$ ), indicating that addition of exogenous 5-HT can rescue the age-related changes in $\mathrm{Ca}^{2+}$ oscillation in pharyngeal $\mathrm{MC}$ neurons of aged animals. Together, these results suggest that dysfunction of serotonergic signaling in aged worms resulted in a reduced activity of its downstream motoneurons.

\section{5-HT/DA decline contributes to age-dependent} behavioral deterioration

Serotonin stimulates pharyngeal pumping through activation of pharyngeal MC and M3 motor neurons that accelerate contrac- 
A

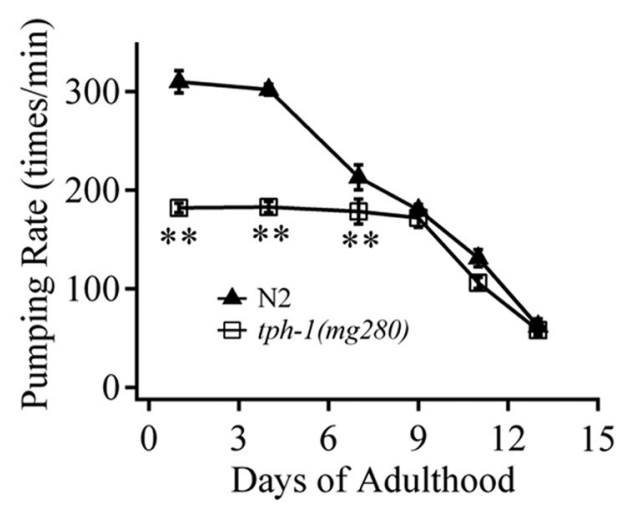

B

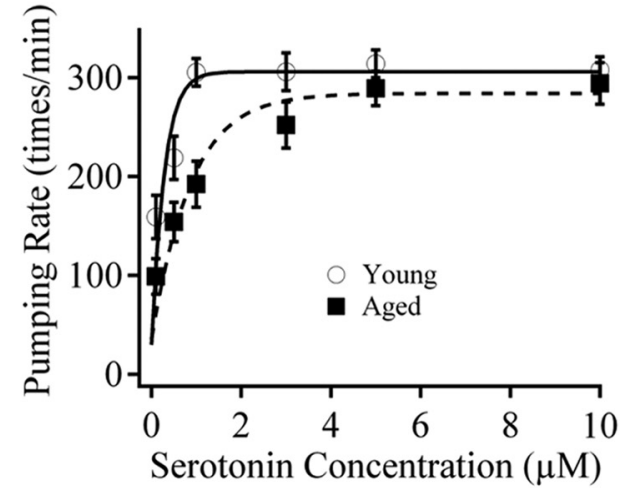

C

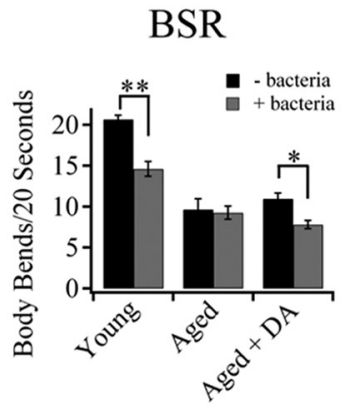

D

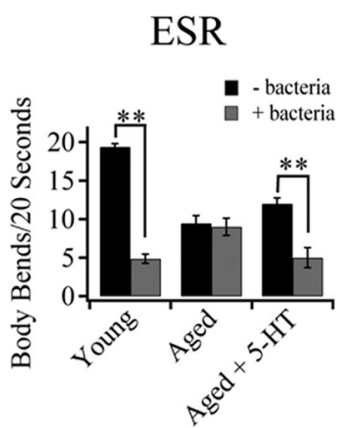

$\mathbf{E}$

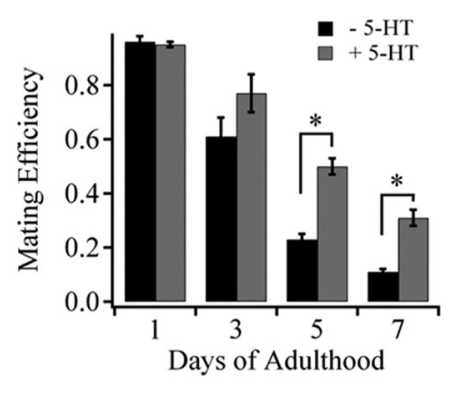

Figure 3. Loss of 5-HT and DA causes behavioral deterioration in aged worms. $\boldsymbol{A}$, Age-dependent changes in pharyngeal pumping rate in $\mathrm{N} 2$ and $5-\mathrm{HT}-\mathrm{deficient} t$ tph-1 (mg280) worms. $\boldsymbol{B}$, Dose-response of exogenous 5-HT on pumping rate of dissected pharynxes from young adult and aged N2 nematodes. The smooth lines are fits to the data. $A, B$, Each data point represents the number of pharyngeal contractions per minute, and $\sim 100$ worms per genotype (or per $5-H T$ concentration) were assayed in at least four independent experiments. $C$, BSR to the presence of food in young adult and aged $\mathrm{N} 2$ worms in the absence or presence of $2.5 \mathrm{~mm}$ DA in cultivating plates. $\boldsymbol{D}$, ESR to the presence of food in young adult and aged N2 worms in the absence or presence of 2.5 mм 5 -HT in cultivating plates. $\boldsymbol{C}, \boldsymbol{D}$, More than 80 worms per condition were tested in four independent experiments. $\boldsymbol{E}$, Age-dependent changes in male mating efficiency of $\mathrm{N} 2$ worms in the absence or presence of $2.5 \mathrm{~mm} 5-\mathrm{HT}$. Approximately 300 males per condition were assayed in seven independent experiments. Data are mean \pm SE. ${ }^{*} p<0.01$ (unpaired Student's $t$ test). ${ }^{* *} p<0.001$ (unpaired Student's $t$ test).

tion-relaxation cycles (Avery, 1993; Niacaris and Avery, 2003). We thus test the hypothesis that the loss of 5-HT contributes to the reduced pharyngeal pumping during aging. As shown in Figure $3 A$, the pumping rate began to decline after day 4 of adulthood in N2 worms. Compared with that of young N2 worms, the pumping rate was much lower in young adult 5-HT-deficient tph-1 (mg280) mutants, although it showed further decline similar to N2 worms after day 9 (Fig. 3A). Furthermore, using dissected pharynx from aged (day 9) N2 adult worms, we found application of exogenous 5-HT dose-dependently recovered the pumping activity to a level comparable with that from the young (day 1) adult N2 worms (Fig. $3 B$ ). These results imply that the reduction of pharyngeal pumping in day 9 aged $\mathrm{N} 2$ worms is the result of the lack of 5-HT. This is consistent with the finding that the difference in pumping rate between young N2 and tph-1 null worms is the result of 5-HT deficiency in $t p h-1$ null worms (Sze et al., 2000). Together, these results show that the loss of 5-HT is responsible for the reduction in pharyngeal pumping during the early stage of aging (day 4-9) and further decline of the pumping rate after day 9 could be attributed to other causes (e.g., muscle deterioration) (Herndon et al., 2002).

In the presence of bacteria, well-fed N2 worms reduce their locomotion, a DA-mediated behavior known as basal slowing response (BSR), which can be quantified by the frequency of body bends (Sawin et al., 2000). Food-deprived wild-type animals, when transferred to assay plates containing a bacteria lawn, undergo a dramatically enhanced slowing response (ESR) to ensure that they do not leave their newly encountered source of food. This experience-dependent ESR is mediated by 5 -HT signaling
(Sawin et al., 2000). We have examined whether the decreased neuronal levels of 5-HT and DA causes deterioration of these behaviors in aged worms. In comparison with clear BSR and ESR in young adult, no detectable BSR and ESR was found in aged N2 worms (Fig. $3 C, D$ ). However, BSR and ESR were recovered in aged N2 worms cultivated in DA- and 5-HT-containing medium (Fig. 3C,D), respectively, indicating that attenuated BSR and ESR were caused by the DA and 5-HT decline in aged worms, respectively.

Male mating efficiency decreases with age before the onset of muscular deterioration or sperm dysfunction (Guo et al., 2012). 5 -HT is necessary for male to sense hermaphrodites and to undergo tail curling during mating (Loer and Kenyon, 1993). The effect of 5-HT on the age-related decay of male mating behavior was thus investigated. N2 males showed a rapid decay in mating efficiency during aging (Fig. $3 E$ ). Surprisingly, the reduction in mating ability of aged N2 males was significantly alleviated by adding $2.5 \mathrm{~mm}$ exogenous 5-HT to the cultivating medium (Fig. $3 E)$. Together, loss of 5-HT/DA results in deterioration of behaviors, including pharyngeal pumping, food-induced slowing responses, and male mating in aged worms.

\section{Longevity manipulations differentially affect 5-HT/DA decline and behavioral deterioration}

Reduction of insulin signaling or mitochondrial function and restriction of food intake have been reported to extend the lifespan of many animals from C. elegans to vertebrates (Lin et al., 1997; Feng et al., 2001; Fontana et al., 2010; Kenyon, 2010). To determine how these longevity manipulations affect age- 
A

A

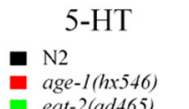

eat-2(ad 465$)$

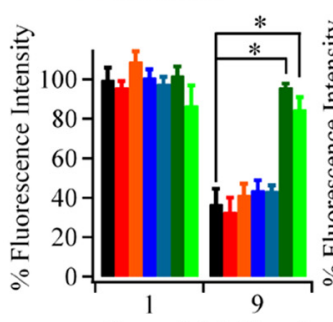

Days of Adulthood
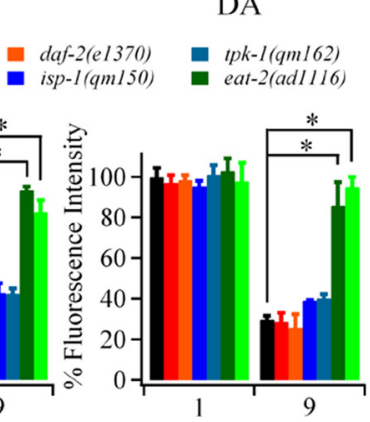

Days of Adulthood
B

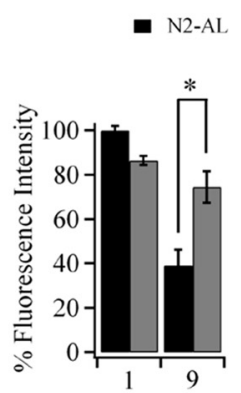

Days of Adulthood
DA

$\square$ N2-DR

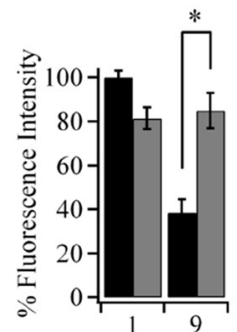

Days of Adulthood
C

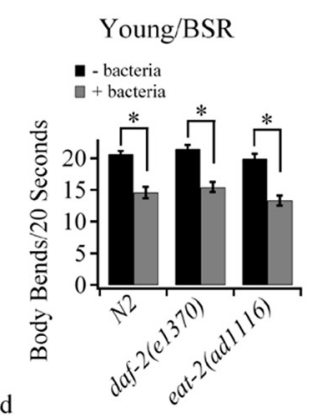

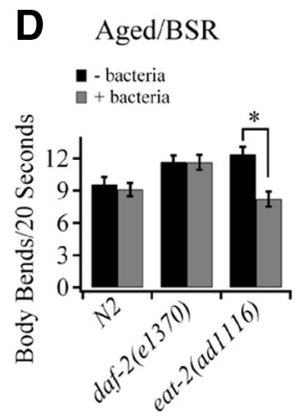
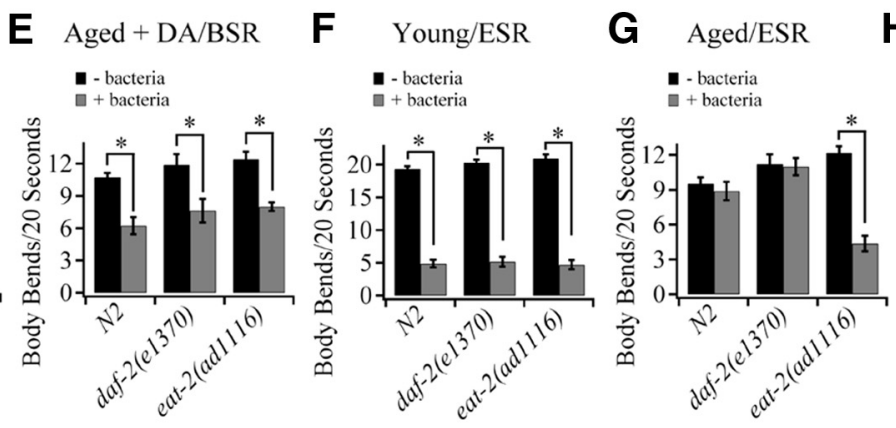

H Aged + 5-HT/ESR

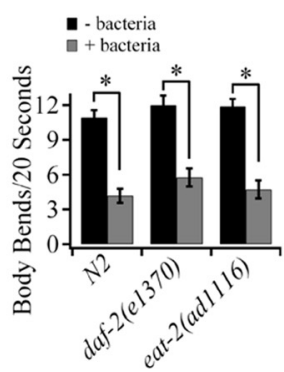

Figure 4. Longevity manipulations differentially affect age-associated decline in 5-HT/DA and behavioral deterioration. A, 5-HT (left) and DA (right) level in NSM and CEP neurons, respectively, of young adult and aged N2, daf-2(e1370), age-1(hx546), isp-1(qm150), tpk-1(qm162), eat-2(ad1116), and eat-2(ad465) animals. More than 30 young and 30 aged worms per genotype were assayed in four independent experiments. 5 -HT level was determined by immunostaining, and DA level was determined by FIF staining. B, 5-HT (left) and DA (right) level in NSM and CEP neurons, respectively, of young adult and aged $\mathrm{N} 2$ worms raised in $\mathrm{AL}(n=33)$ or DR $(n=35)$ condition. The bacterial concentration of $1.0 \times 10^{11} \mathrm{cfu} / \mathrm{ml}$ and $1.0 \times 10^{9} \mathrm{cfu} / \mathrm{ml}$ were used for AL and DR conditions, respectively. C, BSR in well-fed young adult N2, daf-2(e1370), and eat-2(ad1116) animals. $\boldsymbol{D}, \boldsymbol{E}$, BSR in well-fed aged N2, daf-2(e1370), and eat-2(ad1116) in the absence (D) or presence (E) of $2.5 \mathrm{~mm}$ DA in cultivating plates. $\boldsymbol{F}$, ESR in food-deprived young adult N2, daf-2(e1370), and eat-2(ad1116) worms. $\mathbf{G}, \boldsymbol{H}$, ESR in food-deprived aged N2, daf-2(e1370), and eat-2(ad1116) animals in the absence $(\boldsymbol{G})$ or presence $(\boldsymbol{H})$ of $2.5 \mathrm{~mm} 5$-HT in cultivating plates. $\mathbf{C}-\boldsymbol{H}$, Approximately 80 worms per genotype/condition were examined in at least four independent experiments. Data are mean \pm SE. ${ }^{*} p<0.001$.

dependent 5-HT/DA decline, we examined the levels of 5-HT and DA in NSM and CEP neurons, respectively, in six different C. elegans mutants with long lifespan, including insulin signaling-defective mutants daf-2(e1370) and age-1(hx546), mitochondrial function-defective mutants isp-1(qm150) and tpk-1(qm162), as well as DR mutants eat-2(ad1116) and eat2(ad465). We found no significant difference in the neuronal level of 5-HT and DA among all strains in young adult worms (Fig. 4A). The level of 5-HT and DA in mutants with defective insulin signaling or mitochondrial function was found to decrease on day 9 to a similar level as that observed in N2 worms (Fig. 4A). By contrast, we found no significant age-dependent decline in both 5-HT and DA levels in aged DR eat-2(ad1116) and eat-2(ad465) worms (Fig. 4A). We further measured the level of these two transmitters in dietary restricted wild-type $\mathrm{N} 2$ worms. The bacterial concentration of $1.0 \times 10^{11} \mathrm{cfu} / \mathrm{ml}$ and $1.0 \times 10^{9} \mathrm{cfu} / \mathrm{ml}$ were used for $\mathrm{AL}$ and $\mathrm{DR}$ conditions, respectively. Consistent with results from DR mutants, aged $\mathrm{N} 2$ worms under DR condition contained significantly higher level of 5-HT and DA than age-matched N2 worms raised under AL condition (Fig. 4B). Thus, with the exception of DR, lifespan expansion by genetic manipulations did not affect the age-dependent decline in 5-HT and DA levels.

Next, we further examined how these longevity manipulations affect behaviors in aged worms. N2, daf-2(e1370), and eat-2(ad1116) young adult worms displayed similar BSR and ESR (Fig. 4C,F). In aged N2 and daf-2(e1370) mutants, BSR and ESR were totally absent (Fig. $4 D, G$ ) but largely recovered when DA and 5-HT were provided in the cultivating medium, respectively (Fig. 4E,H). By contrast, aged eat-2(ad1116) worms showed clear BSR and ESR (Fig. $4 D, G$ ), similar to those found in young worms (Fig. $4 C, F$ ). The results are consistent with the idea that aged eat-2(ad1116) mutants, but not aged N2 and daf-2(e1370) worms, retained the normal foodinduced behavior because of their sustained high level DA and 5-HT. Together, these results show that extending lifespan does not necessarily delay the age-related 5-HT/DA decline and resultant behavioral deterioration. Furthermore, DR mutants with sustained 5-HT/DA level preserved the normal food-induced behaviors.

\section{PHA-4 upregulates synthesis of 5-HT/DA via expression of BAS-1 with age}

To identify the underlying mechanism for age-dependent reduction in neuronal levels of 5-HT and DA, we examined the expression of genes involved in the biosynthesis and oxidative deamination of 5-HT and DA in both young and aged adult worms. Among these genes, we observed a significant reduction only in the expression of dopa decarboxylase bas-1, the shared enzyme in the synthesis of 5-HT and DA, at the level of mRNA in aged worms ( $63 \pm 4 \%$ of the level in young worms, $p<0.01$; Fig. $5 A$ ). To further examine whether the expression of bas- 1 at the protein level also decreases with age, we expressed bas-1 with fused $g f p$ in N2 worms, using the upstream promoter of bas-1. As shown in Figure 5B, BAS-1::GFP was indeed expressed in both serotonergic and dopaminergic neurons at a high level in young worms and a relatively low level in aged worms (Fig. 5B). Consistent with the amount of reduction in 5-HT and DA levels, we 
A

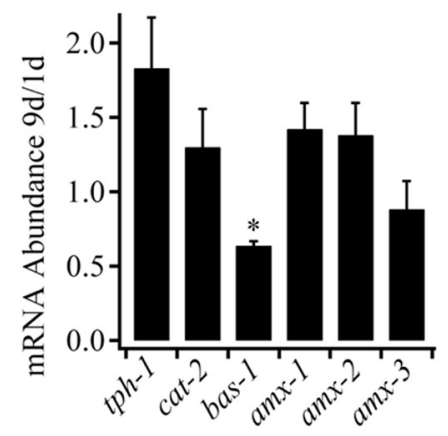

C
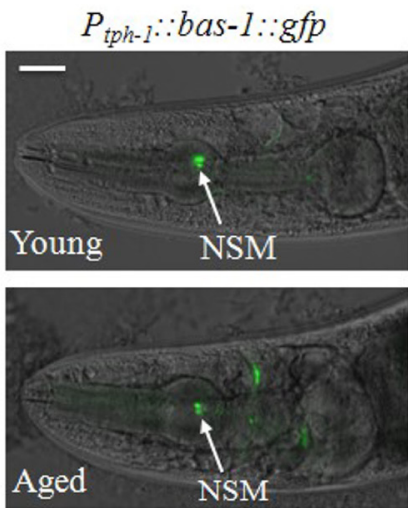
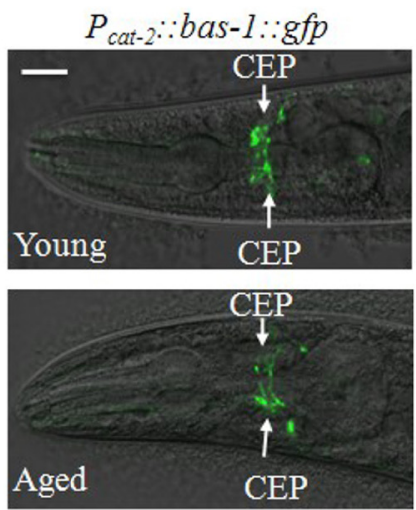

B

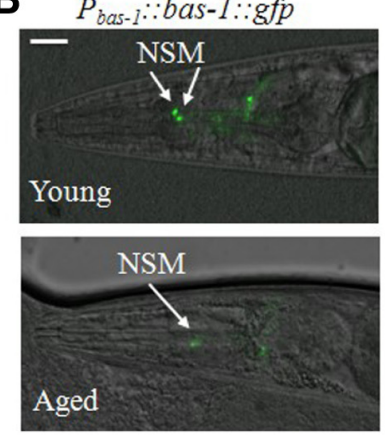

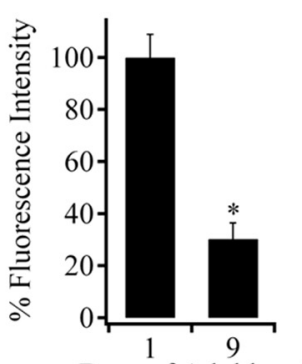

Days of Adulthood
D
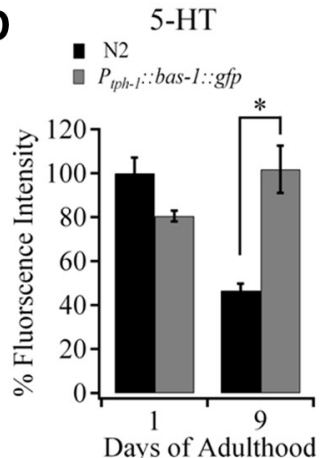

DA

- $\mathrm{N} 2$

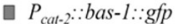

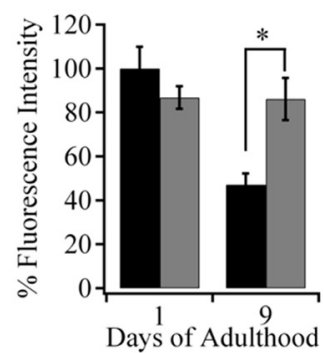

Figure 5. BAS-1 is responsible for the age-dependent decline in neuronal level of 5-HT and DA. A, Age-dependent transcriptional changes of genes that are involved in biosynthesis and oxidative deamination of 5-HT and DA. The act- 1 gene was used as an internal control for RT-PCR. Data are the average of four independent experiments. $\boldsymbol{B}$, Age-dependent changes in expression of BAS-1

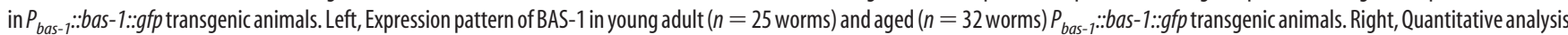

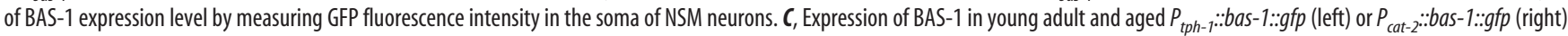

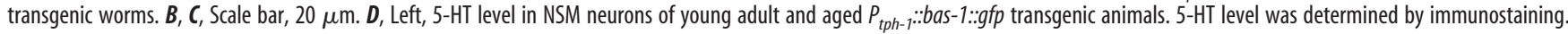
Normalized fluorescence in the young adult and aged transgenic worms were $80 \pm 2 \%$ and $101 \pm 9 \%$, respectively. Right, DA level in CEP neurons of young adult and aged $P_{\text {cat-2 } 2: \text { bas- } 1:: \text { gfp }}$ transgenic animals. DA level was determined by FIF staining. Normalized fluorescence in the young adult and aged transgenic worms were $86 \pm 4 \%$ and $86 \pm 10 \%$, respectively. Approximately 40 young adult and 40 aged worms of each genotype were tested in three independent experiments. In all cases, data are mean \pm SE. ${ }^{*} p<0.01$.

found that GFP fluorescence intensity of NSM neurons, which reflected BAS-1 expression level, in aged worms was $30 \pm 3 \%$ of that in young worms (Fig. 5B).

Is the age-dependent decline in the bas-1 expression responsible for the decline of 5-HT and DA during aging? We examine this issue by overexpressing BAS-1 in serotonergic/ dopaminergic neurons using tph-1/cat-2 upstream promoters, which ought to be effective in driving bas-1 transcription in aged worms because the mRNA levels of $t p h-1$ and cat- 2 were stable in aged worms (Fig. 5A). As expected, BAS-1 expression in both 5-HT and DA neurons remained at a high level in aged $P_{\text {tph-1 }}: \because$ bas-1::gfp and $P_{\text {cat }-2}::$ bas- $1:: g f p$ transgenic worms, respectively (Fig. 5C). Furthermore, the higher expression of BAS-1 also resulted in a high level of 5-HT and DA in aged transgenic worms comparable with that found in young N2 worms (Fig. 5D). A slight 20\% reduction of 5-HT level was found in young $P_{t p h-1}::$ bas-1::gfp transgenic worms, presumably because of competition of transcription factors for $t p h-1$ promoter sites. Thus, the decline in neuronal 5-HT and DA levels in aged worms is the result of the reduced expression of BAS-1.

As we expected, aged eat-2(ad1116) mutants maintained the level of young worms' and aged N2 and daf-2(e1370) worms showed a decreased level of BAS-1 expression (Fig. 6A), consistent with our finding that BAS-1 determines the 5-HT/DA level in aged worms. Longevity genes were then downregulated by RNAi to further test their role in sustaining the high 5-HT/DA level of DR eat-2(ad1116) mutant. In this assay, we introduced SID-1, which could enhance neuronal uptake of dsRNA (Calixto et al., 2010), into the nervous system of eat-2(ad1116) worms. bas-1 RNAi treatment dramatically decreased the BAS-1 level in NSM neurons of eat-2(ad1116); $P_{\text {bas }-1}: \because$ bas-1::gfp; $P_{\text {unc-119 }}::$ sid-1 transgenic worms, suggesting that RNAi silencing works well in the neurons of this transgenic worms (Fig. 6B). L4 hermaphrodite eat-2(ad1116); $P_{\text {bas-1 }}::$ bas-1::gfp; $P_{\text {unc-119 }}::$ sid-1 transgenic worms were then fed with dsRNA targeting longevity genes. Downregulation of transcription factor pha-4, a key regulator for extending lifespan of eat-2(ad1116) mutant (Panowski et al., 2007), significantly reduced BAS-1 level in neurons of eat2(ad1116) worms at day 9, but not at day 4 after RNAi treatment (Fig. 6C). Furthermore, RNAi of bas-1 or pha-4 prevented aged eat-2(ad1116) worms from preserving BSR and ESR behaviors (Fig. 6D). Other longevity genes, including insulin pathway downstream transcription factor daf-16 and other DR-related longevity genes $s k n-1$ and sir-2.1, failed to influence the expression of BAS-1 during aging (Fig. 6C). Together, these results indicate pha-4 regulates the synthesis of 5-HT and DA specifically in late adulthood of animals.

DR evokes pha-4-dependent expression of sod-1, sod-2, sod-4, and sod-5, genes encoding enzymes responsible for scavenging ROS (Panowski et al., 2007). We have also tested whether upregulation of these genes is responsible for preserving the 5-HT/DA level in aged eat-2(ad1116) worms. Downregulation of cytosolic sod-1 and catalases $c t l-1$ and $c t l-3$ resulted in a signifi- 
A

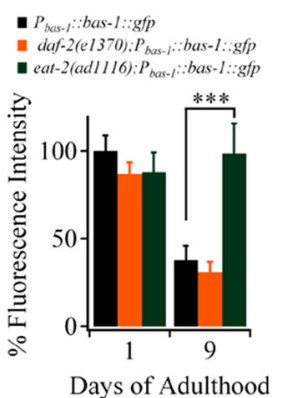

E

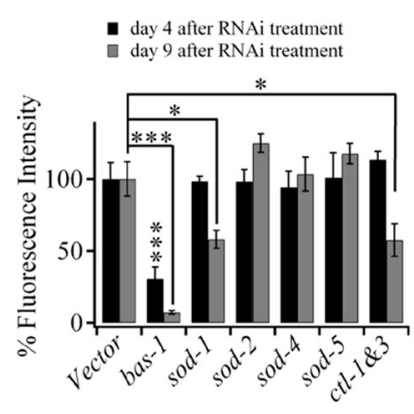

B

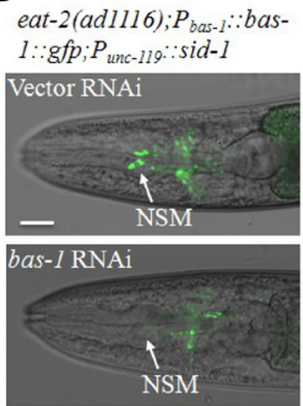

F

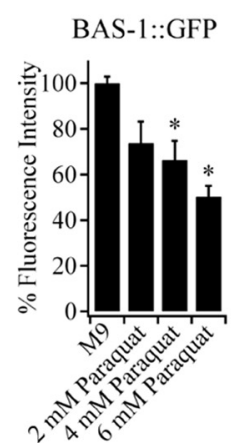

C

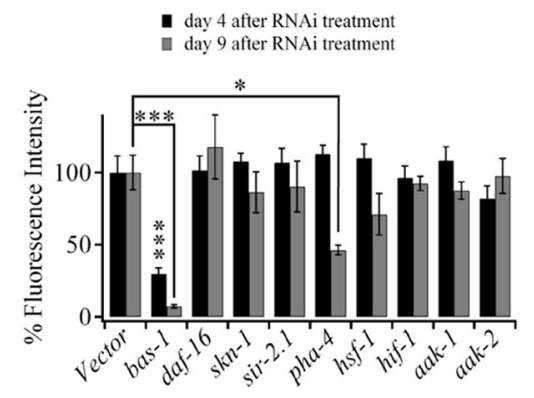

G

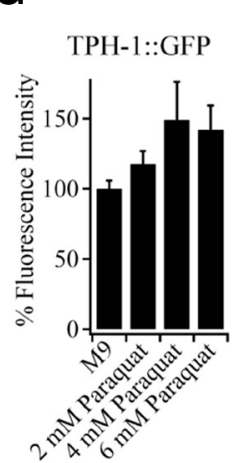

H

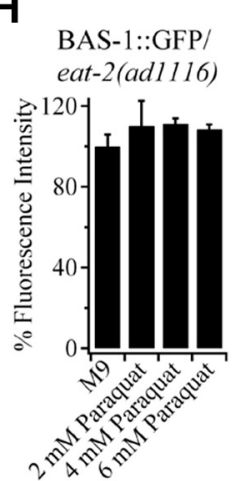

D

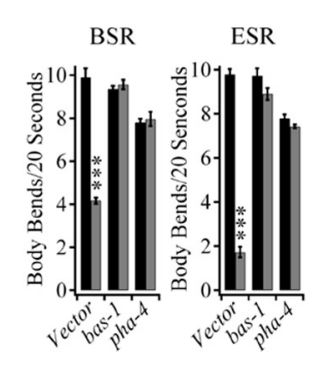

I

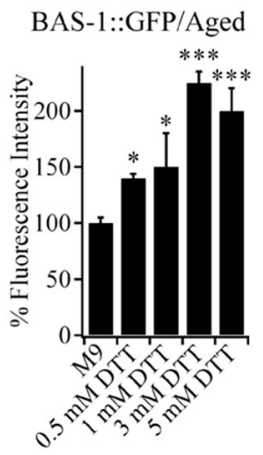

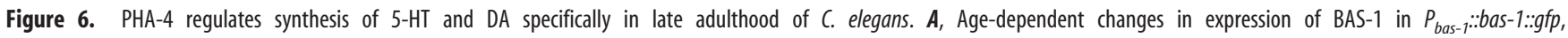

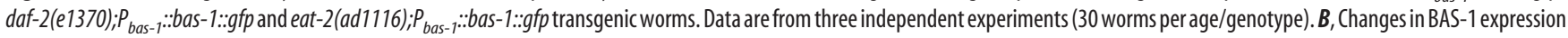

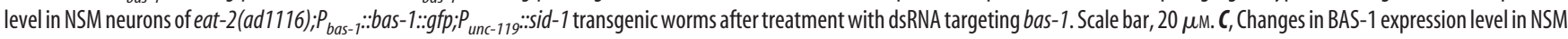

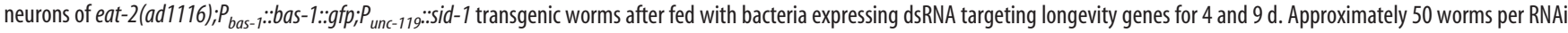

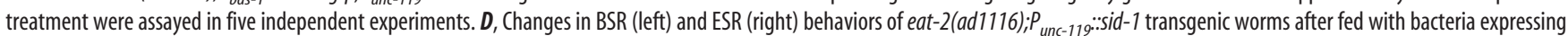
dsRNA targeting bas-1 or pha-4. Approximately 33 worms per condition were assayed in three independent experiments. $\boldsymbol{E}$, Changes in BAS-1 expression level in NSM neurons of

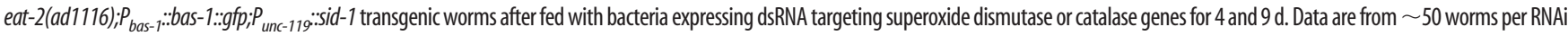

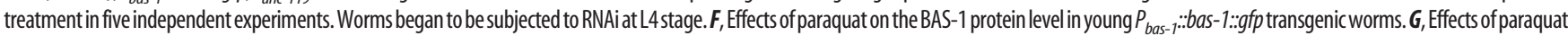

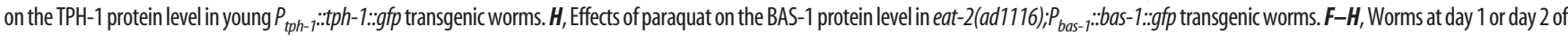
adulthood were treated with paraquat, and the BAS-1 and TPH-1 level was analyzed $3 \mathrm{~d}$ after treatments. More than 30 worms per condition were examined in at least three independent experiments. $I$, Effects

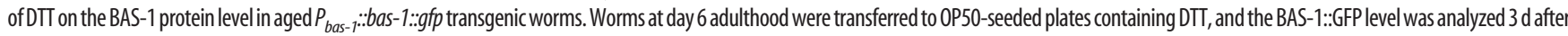
treatment. Approximately 30 worms per concentration were tested in three independent experiments. Data are mean \pm SE. ${ }^{*} p<0.05$ (unpaired Student's $t$ test). ${ }^{* *} p<0.01$ (unpaired Student's $t$ test). ${ }^{* * *} p<0.001$ (unpaired Student's t test).

cant reduction of BAS-1 expression in eat-2(ad1116) worms at day 9, but not at day 4 after RNAi treatment (Fig. 6E). By contrast, other sod genes marginally affected the neuronal BAS-1 level (Fig. $6 E)$. This difference may be attributed to distinct expression pattern and cellular localization among sod gene products.

We then examined the effect of oxidizing and reducing agents on the expression of BAS- 1 to test the hypothesis that age-related accumulation of ROS contributes to reduced level of 5-HT and DA. Young adult $P_{\text {bas }-1}:: b a s-1:: g f p$ transgenic worms were then treated with paraqaut, a ROS-inducing reagent for $3 \mathrm{~d}$, and we found that BAS-1 protein level in those worms was significantly lower than that in worms treated with M9 buffer (Fig. 6F). By contrast, the expression of TPH-1 was not affected by paraqaut (Fig. 6G). The result is consistent with the finding that the transcription of bas-1, but not tph-1, declines with age (Fig. 5A). DR eat-2(ad1116) worms showed resistance to paraqaut (Fig. $6 H$ ), presumably because of the upregulation of sod genes. Furthermore, the BAS- 1 level in aged N2 worms increased up to $>2$-fold after treatment with various concentrations of reducing agent DTT (Fig. 6I), suggesting that the age-related decline in BAS-1 level could be prevented by reducing ROS level. Together, these results imply that increasing ROS level attenuates the synthesis of 5-HT/DA in aged C. elegans, and the sustained level of 5-HT/DA in aged eat-2(ad1116) worms is the result of the action of PHA-4 transcription factor.

\section{Elevation of endogenous 5-HT/DA preserves behaviors in aged worms}

As shown in Figure 5D, $P_{t p h-1}:: b a s-1:: g f p$ and $P_{\text {cat-2 } 2: \text { bas- } 1:: g f p}$ transgenic worms retained high levels of 5-HT and DA, respectively, during aging. To inquire whether elevating endogenous 5-HT/DA level improves life quality of aging C. elegans, we examined three important behaviors (pharyngeal pumping, food-induced slowing response, and male mating) in aged

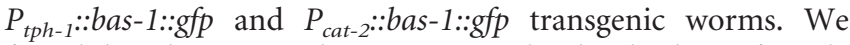
found that elevating endogenous 5-HT level indeed significantly delayed the reduction of pharyngeal pumping in both $\mathrm{N} 2$ and long-lived daf-2(e1370) worms during day 4-12 of adulthood (Fig. 7A). In the late stage of aging (>day 12), the effect was still present in N2 but not in daf-2(e1370) worms. Behavioral deterioration in worms of the advanced age is likely to be caused by massive muscle deterioration rather than the low 5-HT level. Long-lived daf-2(e1370) mutant is known to exhibit delayed muscle sarcopenia (Herndon et al., 2002) and thus may preserve pharyngeal pumping at a level higher than that in N2 worms in the very late adulthood (Fig. 7A). 
A

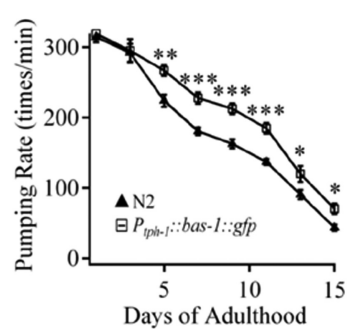

B

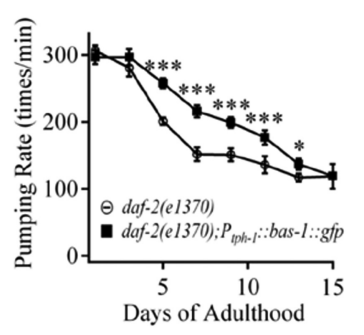

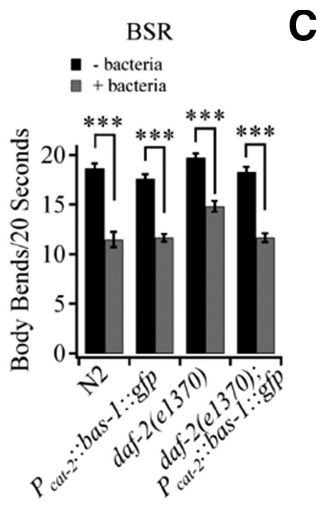

C

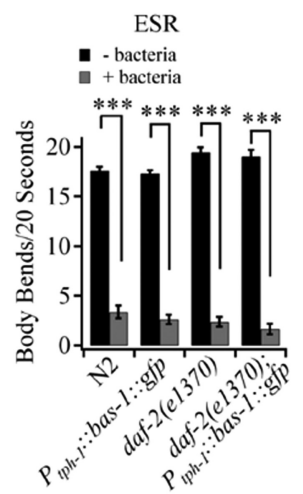

D

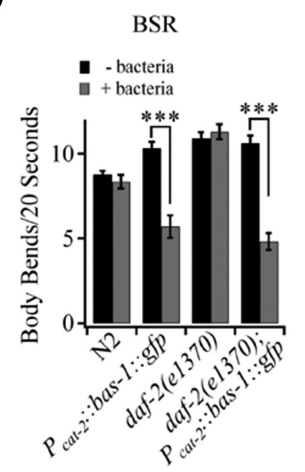

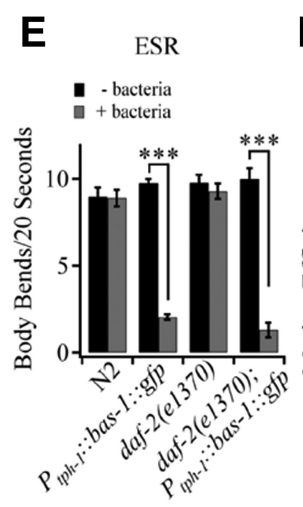

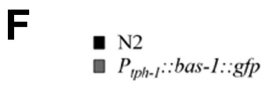

- $\mathrm{N} 2$

- eat-2(ad1116)

G
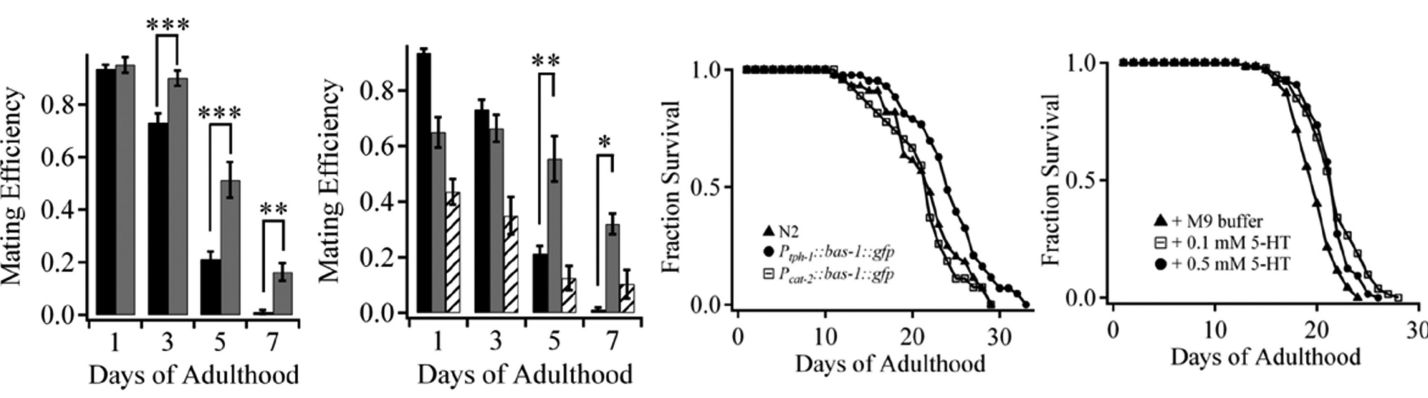

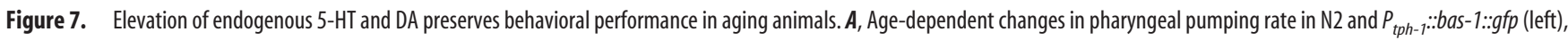
daf-2(e1370) and daf-2(e1370); $P_{\text {tph-1 }}: \because$ bas-1::gfp (right) transgenic worms. Each data point represents the average number of pharyngeal contractions per minute. Data are from $>100$ worms per

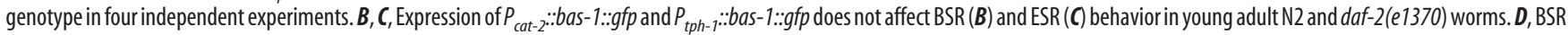

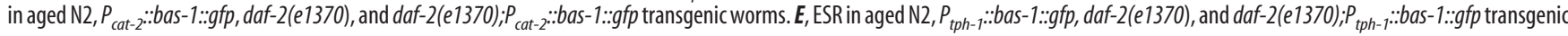
worms. $\boldsymbol{B}-\boldsymbol{E}$, Data are from $>30$ worms per genotype in three independent experiments. $\boldsymbol{F}$, Left, Age-dependent changes in male mating efficiency of $\mathrm{N} 2$ and $P_{t p h-1}::$ bas $-1:: g f p$ transgenic animals. Right, Age-related changes in mating efficiency of N2, eat-2(ad1116), and daf-2(e1370) males. Data are from $\sim 200$ males per genotype/age in five independent experiments. G, Left, Lifespan curve

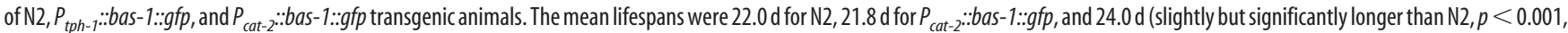

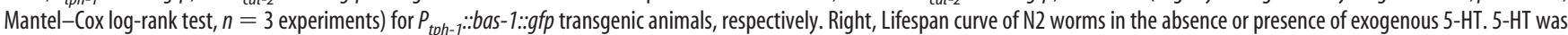
added after day 5 of adulthood. The mean lifespans of $\mathrm{N} 2$ worms treated with $0.1 \mathrm{~mm}(21.3 \mathrm{~d}, p<0.001$, Mantel-Cox log-rank test, $n=5$ experiments) and $0.5 \mathrm{~mm}(21.1 \mathrm{~d}, p<0.001$, Mantel-Cox log-rank test, $n=3$ experiments) 5 -HT were significantly longer than that of control worms (19.2 d). $\boldsymbol{A}-\boldsymbol{F}$, Data are mean \pm SE. ${ }^{*} p<0.05$ (unpaired Student's $t$ test). ${ }^{* *} p<0.01$ (unpaired Student's $t$ test). ${ }^{* * *} p<0.001$ (unpaired Student's $t$ test).

We also found that the expression of $P_{t p h-1}:: b a s-1:: g f p$ and $P_{\text {cat-2: }}:$ bas-1::gfp did not affect BSR and ESR behaviors in young adult N2 and daf-2(e1370) worms (Fig. 7 B,C). Nevertheless, aged

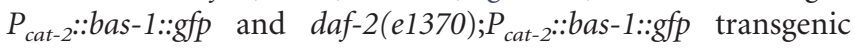
worms prevented the decay of food-induced BSR behavior (Fig. $7 D)$, and aged $P_{t p h-1}:: b a s-1:: g f p$ and $d a f-2(e 1370) ; P_{t p h-1}:: b a s-1:: g f p$ transgenic worms displayed clear ESR behaviors (Fig. 7E). The result is consistent with the idea that elevation of DA/5-HT level in aged worms can preserve food-induced slowing response behaviors.

Elevation of endogenous 5-HT level by expressing $P_{t p h-1}:$ bas$1:: g f p$ also significantly improved male mating efficiency in males at day 3, 5, and 7 of adulthood (Fig. 7F). Although young eat2(ad1116) males exhibited a mild defect in their mating ability (70\% of that in young $\mathrm{N} 2$ males), elder eat-2(ad1116) males (>day 5) maintained higher mating efficiency than that of N2 age-matched males (Fig. $7 F$ ), supporting the idea that sustained endogenous 5-HT in aged eat-2(ad1116) males contributes to the delay of the deterioration in mating behavior. The male mating ability of daf-2(e1370) worms was seriously impaired, even in young adults and the ability further declined with age (Fig. $7 F$ ). We therefore did not further examine whether elevation of 5-HT affects aging daf-2(e1370) male's mating ability. Together, these results show that elevation of endogenous 5-HT/DA level ameliorates behavioral impairment during aging.

Finally, we examined whether maintenance of high 5-HT/DA level affects the worm's lifespan. We found a slight but significant extension of lifespan in the transgenic worms compared with N2 worms when BAS-1 was expressed in serotonergic neurons (with $P_{t p h-1}:: b a s-1:: g f p$ ) but not in dopaminergic neuron

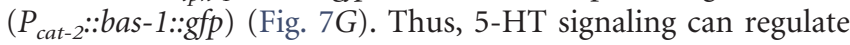
the lifespan of C. elegans. The finding was further supported by observations that the mean lifespan of $\mathrm{N} 2$ worms also was significantly extended by adding exogenous 0.1 or $0.5 \mathrm{~mm} 5-\mathrm{HT}$ in the cultivating medium after day 5 of adulthood (Fig. $7 G$ ).

\section{Discussion}

In this study, we found that the loss of 5-HT/DA causes deterioration of several important behaviors, including pharyngeal pumping, food-induced slowing responses, and male mating in aged C. elegans. DR delayed the age-related decline of 5-HT/DA level and prevented the behavioral decline, and this effect was mediated through the action of transcriptional factor PHA-4 and its downstream ROS scavenging enzymes. Furthermore, elevation of endogenous 5-HT/DA by elevating BAS-1 expression helped to promote behavioral performance 
in aged wild-type and long-lived daf-2(e1370) worms. These results underscore 5-HT/DA decline as the cause of behavioral deterioration in aged animals and suggest the potential benefit of elevating 5-HT/DA level in ameliorating the dysfunction of the aging nervous systems.

\section{Regulation of 5-HT/DA level during aging}

Significant losses of DA/5-HT and their receptors over normal lifespan have often been reported in mammals (Lu et al., 2004; Ota et al., 2006; Kumakura et al., 2010). An age-dependent increase in the expression of TPH-1 has been reported (Murakami et al., 2008), arguing an elevation of serotonin signaling in the early stage of aging in C. elegans. However, the level of 5-HT and its receptor in aged worms was not determined in the latter study. We found that the second synthetic enzyme BAS-1, but not TPH1/CAT-2, becomes the rate-limiting enzyme for 5-HT/DA synthesis when BAS-1 level markedly declines in aged worms because overexpression of BAS-1 significantly increases the 5-HT/DA level in aged, but not young worms.

Our data also identified the transcription factor PHA-4 as an age-dependent regulator for the synthesis of 5-HT/DA. It is known that PHA-4 expression is increased in response to DR and downregulation of PHA-4 with RNAi suppresses lifespan extension (Panowski et al., 2007). However, the effect of PHA-4 on the 5-HT/DA signaling in aged worms is not simply due to lifespan extension because other transcription factors that affect lifespan of C. elegans (e.g., DAF-16 and SKN-1) did not significantly influence the neuronal level of BAS-1 in aged worms.

In this study, we found that PHA-4 upregulates the synthesis of 5-HT/DA through its action on downstream gene sod-1 and catalases in aged worms, indicating that increasing ROS levels may diminish the expression level of BAS-1, although the precise mechanism remains to be elucidated. The nervous system is particularly susceptible to the effect of ROS, as increased oxidative damage is readily detectable in the aging brain in many animals, through their actions on neuronal ion channels and receptors (Landfield and Pitler, 1984; Toescu and Verkhratsky, 2000; Power et al., 2002; Cai and Sesti, 2009; Cotella et al., 2012). Here, we also show that ROS could affect age-related alteration in the synthesis of neurotransmitters. The redox state thus is an important factor for mediating neuronal aging.

\section{Behavioral deterioration during aging in $C$. elegans}

Dramatic decline in general behaviors, such as locomotion and feeding observed in very late adulthood, is usually attributed to the muscle sarcopenia characterized by muscle atrophy in C. elegans (Herndon et al., 2002). However, the animal's behavior starts to deteriorate as early as midlife adulthood, and distinct mechanisms may be responsible for behavioral deterioration in early versus late stage of aging. We found that elevating the 5-HT/DA level ameliorates age-related decline in the worm's behaviors, including pharyngeal pumping, foodinduced slowing response, and male mating during the early stage of aging, before extensive muscle deterioration. Our finding supports the idea that elevating 5-HT/DA level at the time when motor system remains functional helps to improve the worms' behavior. This is also consistent with the observation that most muscles in C. elegans retain normal sarcomere organization and the functional decline in neurotransmission significantly contributes to the progressive deterioration in motor ability at the early stage of aging (Glenn et al., 2004; Liu et al., 2013).
Evidence from human studies suggests that the decline in the transmitter signaling begins in the 30s (Wong et al., 1984; Rinne et al., 1990; Wang et al., 1998; Kaasinen et al., 2000; Ota et al., 2006; Kumakura et al., 2010), prompting the idea that alteration of neurotransmission may underlie mid-age decline in human behaviors, including locomotive efficacy and flexibility, as well as some cognitive functions. Our finding argues that improved neurotransmitter signaling may be one strategy for ameliorating agerelated behavioral impairment.

\section{Longevity genes differentially influence behavior deterioration}

Longevity genes have been reported to delay the onset of aging and age-related diseases (Morley et al., 2002; Cohen et al., 2006; Pinkston et al., 2006). However, a previous study showed that the long-lived age-1 (hx546) mutant delays the appearance of only some of the cellular markers of aging (Herndon et al., 2002), suggesting that the longevity gene may only affect some aspects of aging. In support of this notion, whereas other studies have revealed that longevity genes daf-2 and daf-16 regulate age-dependent neurite branching (Pan et al., 2011; Tank et al., 2011; Toth et al., 2012), we found that they do not affect the 5-HT/DA level. On the other hand, another longevity gene pha-4, which does not affect neurite branching (Pan et al., 2011; Tank et al., 2011; Toth et al., 2012), was shown here to elevate the 5-HT/DA level. These findings suggest that age-related changes in neuronal morphology and transmitter functions are regulated by independent molecular mechanisms. Thus, specific longevity manipulation only partially delays the aging of the nervous system.

Age-related behavioral decline in C. elegans has been well documented (Huang et al., 2004). Longevity mutations daf-2(e1370), age-1(hx546), and eat-2(ad1116) delay the onset of age-related muscle sarcopenia (Herndon et al., 2002) and enhance locomotive activity, isothermal tracking, as well as chemotaxis behavior in aging populations (Glenn et al., 2004; Huang et al., 2004; Murakami et al., 2005). However, lifespan extension does not necessarily delay all age-related behavioral and cognitive declines. In this study, we found that the longevity mutant daf-2(e1370) exhibited significant defect in male mating behavior, even in young adults, and there was no delay in age-related decline of some important behaviors, including pharyngeal pumping and foodinduced slowing responses during early stage of aging. By contrast, eat-2(ad1116) worms delayed the decay of these behaviors during aging. Consistent with our findings, eat-2(ad1116) worms, but not daf-2(e1370) worms, have been reported to maintain long-term memory during aging (Kauffman et al., 2010). Dissociation of lifespan extension and age-related behavioral impairment has also been reported in Drosophila (CookWiens and Grotewiel, 2002; Yamazaki et al., 2007) and mammals (Neff et al., 2013). A comprehensive study on how specific longevity gene affects age-related behavioral decline therefore will provide useful clues to therapeutic approaches for improving the quality of life in aged individuals.

\section{Notes}

Supplemental material for this article is available at http://www.ion.ac. $\mathrm{cn} /$ laboratories/publication.asp?id=71. The supplemental material consists of two supplemental figures and one movie. Supplemental Figure S1 and Movie show the expression pattern of $P f l p-21:: G C a M P 3$ and a rhythmic $\mathrm{Ca}^{2+}$ oscillation in MC neuron, respectively; Supplemental Figure S2 suggests that RNAi of pha-4 accelerates age-related decay in BSR and ESR. This material has not been peer reviewed. 


\section{References}

Andrews-Hanna JR, Snyder AZ, Vincent JL, Lustig C, Head D, Raichle ME, Buckner RL (2007) Disruption of large-scale brain systems in advanced aging. Neuron 56:924-935. CrossRef Medline

Avery L (1993) Motor neuron M3 controls pharyngeal muscle relaxation timing in Caenorhabditis elegans. J Exp Biol 175:283-297. Medline

Avery L, Horvitz HR (1989) Pharyngeal pumping continues after laser killing of the pharyngeal nervous system of C. elegans. Neuron 3:473-485. CrossRef Medline

Bishop NA, Lu T, Yankner BA (2010) Neural mechanisms of ageing and cognitive decline. Nature 464:529-535. CrossRef Medline

Braskie MN, Wilcox CE, Landau SM, O’Neil JP, Baker SL, Madison CM, Kluth JT, Jagust WJ (2008) Relationship of striatal dopamine synthesis capacity to age and cognition. J Neurosci 28:14320-14328. CrossRef Medline

Cai SQ, Sesti F (2009) Oxidation of a potassium channel causes progressive sensory function loss during aging. Nat Neurosci 12:611-617. CrossRef Medline

Calixto A, Chelur D, Topalidou I, Chen X, Chalfie M (2010) Enhanced neuronal RNAi in C. elegans using SID-1. Nat Methods 7:554-559. CrossRef Medline

Chase DL, Koelle MR (2007) Biogenic amine neurotransmitters in C. elegans. WormBook 1-15.

Chen D, Thomas EL, Kapahi P (2009) HIF-1 modulates dietary restrictionmediated lifespan extension via IRE-1 in Caenorhabditis elegans. PLoS Genet 5:e1000486. CrossRef Medline

Cohen E, Bieschke J, Perciavalle RM, Kelly JW, Dillin A (2006) Opposing activities protect against age-onset proteotoxicity. Science 313:16041610. CrossRef Medline

Cook-Wiens E, Grotewiel MS (2002) Dissociation between functional senescence and oxidative stress resistance in Drosophila. Exp Gerontol 37: 1347-1357. CrossRef Medline

Cotella D, Hernandez-Enriquez B, Wu X, Li R, Pan Z, Leveille J, Link CD, Oddo S, Sesti F (2012) Toxic role of $\mathrm{K}^{+}$channel oxidation in mammalian brain. J Neurosci 32:4133-4144. CrossRef Medline

Dreher JC, Meyer-Lindenberg A, Kohn P, Berman KF (2008) Age-related changes in midbrain dopaminergic regulation of the human reward system. Proc Natl Acad Sci U S A 105:15106-15111. CrossRef Medline

Feng J, Bussière F, Hekimi S (2001) Mitochondrial electron transport is a key determinant of life span in Caenorhabditis elegans. Dev Cell 1:633644. CrossRef Medline

Fontana L, Partridge L, Longo VD (2010) Extending healthy life span: from yeast to humans. Science 328:321-326. CrossRef Medline

Glenn CF, Chow DK, David L, Cooke CA, Gami MS, Iser WB, Hanselman KB, Goldberg IG, Wolkow CA (2004) Behavioral deficits during early stages of aging in Caenorhabditis elegans result from locomotory deficits possibly linked to muscle frailty. J Gerontol A Biol Sci Med Sci 59:1251-1260. CrossRef Medline

Grady C (2012) The cognitive neuroscience of ageing. Nat Rev Neurosci 13:491-505. CrossRef Medline

Guo X, Navetta A, Gualberto DG, García LR (2012) Behavioral decay in aging male C. elegans correlates with increased cell excitability. Neurobiol Aging 33:1483. CrossRef Medline

Herndon LA, Schmeissner PJ, Dudaronek JM, Brown PA, Listner KM, Sakano Y, Paupard MC, Hall DH, Driscoll M (2002) Stochastic and genetic factors influence tissue-specific decline in ageing C. elegans. Nature 419:808-814. CrossRef Medline

Horvitz HR, Chalfie M, Trent C, Sulston JE, Evans PD (1982) Serotonin and octopamine in the nematode Caenorhabditis elegans. Science 216:10121014. CrossRef Medline

Huang C, Xiong C, Kornfeld K (2004) Measurements of age-related changes of physiological processes that predict lifespan of Caenorhabditis elegans. Proc Natl Acad Sci U S A 101:8084-8089. CrossRef Medline

Kaasinen V, Vilkman H, Hietala J, Någren K, Helenius H, Olsson H, Farde L, Rinne J (2000) Age-related dopamine D2/D3 receptor loss in extrastriatal regions of the human brain. Neurobiol Aging 21:683-688. CrossRef Medline

Kamath RS, Fraser AG, Dong Y, Poulin G, Durbin R, Gotta M, Kanapin A, Le Bot N, Moreno S, Sohrmann M, Welchman DP, Zipperlen P, Ahringer J (2003) Systematic functional analysis of the Caenorhabditis elegans genome using RNAi. Nature 421:231-237. CrossRef Medline

Kauffman AL, Ashraf JM, Corces-Zimmerman MR, Landis JN, Murphy CT
(2010) Insulin signaling and dietary restriction differentially influence the decline of learning and memory with age. PLoS Biol 8:e1000372. CrossRef Medline

Kenyon CJ (2010) The genetics of ageing. Nature 464:504-512. CrossRef Medline

Kumakura Y, Vernaleken I, Buchholz HG, Borghammer P, Danielsen E, Gründer G, Heinz A, Bartenstein P, Cumming P (2010) Age-dependent decline of steady state dopamine storage capacity of human brain: an FDOPA PET study. Neurobiol Aging 31:447-463. CrossRef Medline

Landfield PW, Pitler TA (1984) Prolonged $\mathrm{Ca}^{2+}$-dependent afterhyperpolarizations in hippocampal neurons of aged rats. Science 226:1089-1092. CrossRef Medline

Lin K, Dorman JB, Rodan A, Kenyon C (1997) daf-16: an HNF-3/forkhead family member that can function to double the life-span of Caenorhabditis elegans. Science 278:1319-1322. CrossRef Medline

Lints R, Emmons SW (1999) Patterning of dopaminergic neurotransmitter identity among Caenorhabditis elegans ray sensory neurons by a TGFbeta family signaling pathway and a Hox gene. Development 126:5819-5831. Medline

Liu J, Zhang B, Lei H, Feng Z, Liu J, Hsu AL, Xu XZ (2013) Functional aging in the nervous system contributes to age-dependent motor activity decline in C. elegans. Cell Metab 18:392-402. CrossRef Medline

Loer CM, Kenyon CJ (1993) Serotonin-deficient mutants and male mating behavior in the nematode Caenorhabditis elegans. J Neurosci 13:54075417. Medline

Lu T, Pan Y, Kao SY, Li C, Kohane I, Chan J, Yankner BA (2004) Gene regulation and DNA damage in the ageing human brain. Nature 429:883891. CrossRef Medline

Makman MH, Stefano GB (1993) Neuroregulatory mechanisms in aging, Ed 1. Oxford: Pergamon.

Meltzer CC, Smith G, DeKosky ST, Pollock BG, Mathis CA, Moore RY, Kupfer DJ, Reynolds CF 3rd (1998) Serotonin in aging, late-life depression, and Alzheimer's disease: the emerging role of functional imaging. Neuropsychopharmacology 18:407-430. CrossRef Medline

Morley JF, Brignull HR, Weyers JJ, Morimoto RI (2002) The threshold for polyglutamine-expansion protein aggregation and cellular toxicity is dynamic and influenced by aging in Caenorhabditis elegans. Proc Natl Acad Sci U S A 99:10417-10422. CrossRef Medline

Morrison JH, Baxter MG (2012) The ageing cortical synapse: hallmarks and implications for cognitive decline. Nat Rev Neurosci 13:240-250. CrossRef Medline

Murakami H, Bessinger K, Hellmann J, Murakami S (2005) Agingdependent and -independent modulation of associative learning behavior by insulin/insulin-like growth factor-1 signal in Caenorhabditis elegans. J Neurosci 25:10894-10904. CrossRef Medline

Murakami H, Bessinger K, Hellmann J, Murakami S (2008) Manipulation of serotonin signal suppresses early phase of behavioral aging in Caenorhabditis elegans. Neurobiol Aging 29:1093-1100. CrossRef Medline

Neff F, Flores-Dominguez D, Ryan DP, Horsch M, Schröder S, Adler T, Afonso LC, Aguilar-Pimentel JA, Becker L, Garrett L, Hans W, Hettich MM, Holtmeier R, Hölter SM, Moreth K, Prehn C, Puk O, Rácz I, Rathkolb B, Rozman J, et al. (2013) Rapamycin extends murine lifespan but has limited effects on aging. J Clin Invest 123:3272-3291. CrossRef Medline

Niacaris T, Avery L (2003) Serotonin regulates repolarization of the C. elegans pharyngeal muscle. J Exp Biol 206:223-231. CrossRef Medline

Ota M, Yasuno F, Ito H, Seki C, Nozaki S, Asada T, Suhara T (2006) Agerelated decline of dopamine synthesis in the living human brain measured by positron emission tomography with L-[beta-11C]DOPA. Life Sci 79: 730-736. CrossRef Medline

Pan CL, Peng CY, Chen CH, McIntire S (2011) Genetic analysis of agedependent defects of the Caenorhabditis elegans touch receptor neurons. Proc Natl Acad Sci U S A 108:9274-9279. CrossRef Medline

Panowski SH, Wolff S, Aguilaniu H, Durieux J, Dillin A (2007) PHA-4/Foxa mediates diet-restriction-induced longevity of C. elegans. Nature 447: 550-555. CrossRef Medline

Pinkston JM, Garigan D, Hansen M, Kenyon C (2006) Mutations that increase the life span of C. elegans inhibit tumor growth. Science 313:971975. CrossRef Medline

Power JM, Wu WW, Sametsky E, Oh MM, Disterhoft JF (2002) Age-related enhancement of the slow outward calcium-activated potassium current in 
hippocampal CA1 pyramidal neurons in vitro. J Neurosci 22:7234-7243. Medline

Rinne JO, Lönnberg P, Marjamäki P (1990) Age-dependent decline in human brain dopamine D1 and D2 receptors. Brain Res 508:349-352. CrossRef Medline

Rogers C, Reale V, Kim K, Chatwin H, Li C, Evans P, de Bono M (2003) Inhibition of Caenorhabditis elegans social feeding by FMRFamiderelated peptide activation of NPR-1. Nat Neurosci 6:1178-1185. CrossRef Medline

Sawin ER, Ranganathan R, Horvitz HR (2000) C. elegans locomotory rate is modulated by the environment through a dopaminergic pathway and by experience through a serotonergic pathway. Neuron 26:619-631. CrossRef Medline

Shimozono S, Fukano T, Kimura KD, Mori I, Kirino Y, Miyawaki A (2004) Slow $\mathrm{Ca}^{2+}$ dynamics in pharyngeal muscles in Caenorhabditis elegans during fast pumping. EMBO Rep 5:521-526. CrossRef Medline

Sulston J, Dew M, Brenner S (1975) Dopaminergic neurons in the nematode Caenorhabditis elegans. J Comp Neurol 163:215-226. CrossRef Medline

Sze JY, Victor M, Loer C, Shi Y, Ruvkun G (2000) Food and metabolic signalling defects in a Caenorhabditis elegans serotonin-synthesis mutant. Nature 403:560-564. CrossRef Medline

Tank EM, Rodgers KE, Kenyon C (2011) Spontaneous age-related neurite branching in Caenorhabditis elegans. J Neurosci 31:9279-9288. CrossRef Medline
Tian L, Hires SA, Mao T, Huber D, Chiappe ME, Chalasani SH, Petreanu L, Akerboom J, McKinney SA, Schreiter ER, Bargmann CI, Jayaraman V, Svoboda K, Looger LL (2009) Imaging neural activity in worms, flies and mice with improved GCaMP calcium indicators. Nat Methods 6:875881. CrossRef Medline

Toescu EC, Verkhratsky A (2000) Parameters of calcium homeostasis in normal neuronal ageing. J Anat 197:563-569. CrossRef Medline

Toth ML, Melentijevic I, Shah L, Bhatia A, Lu K, Talwar A, Naji H, IbanezVentoso C, Ghose P, Jevince A, Xue J, Herndon LA, Bhanot G, Rongo C, Hall DH, Driscoll M (2012) Neurite sprouting and synapse deterioration in the aging Caenorhabditis elegans nervous system. J Neurosci 32: 8778-8790. CrossRef Medline

Wang Y, Chan GL, Holden JE, Dobko T, Mak E, Schulzer M, Huser JM, Snow BJ, Ruth TJ, Calne DB, Stoessl AJ (1998) Age-dependent decline of dopamine D1 receptors in human brain: a PET study. Synapse 30:56-61. CrossRef Medline

Wong DF, Wagner HN Jr, Dannals RF, Links JM, Frost JJ, Ravert HT, Wilson AA, Rosenbaum AE, Gjedde A, Douglass KH (1984) Effects of age on dopamine and serotonin receptors measured by positron tomography in the living human brain. Science 226:1393-1396. CrossRef Medline

Yamazaki D, Horiuchi J, Nakagami Y, Nagano S, Tamura T, Saitoe M (2007) The Drosophila DCO mutation suppresses age-related memory impairment without affecting lifespan. Nat Neurosci 10:478-484. CrossRef Medline 